\title{
The Impact of Aircraft Dropsonde and Satellite Wind Data on Numerical Simulations of Two Landfalling Tropical Storms during the Tropical Cloud Systems and Processes Experiment
}

\author{
Zhaoxia Pu And Xuanli Li \\ Department of Meteorology, University of Utah, Salt Lake City, Utah \\ Christopher S. Velden \\ Cooperative Institute for Meteorological Satellite Studies, University of Wisconsin-Madison, Madison, Wisconsin \\ SiM D. ABERSON \\ NOAA/Hurricane Research Division, Miami, Florida \\ W. Timothy LiU \\ Jet Propulsion Laboratory, California Institute of Technology, Pasadena, California
}

(Manuscript received 17 January 2007, in final form 27 June 2007)

\begin{abstract}
Dropwindsonde, Geostationary Operational Environmental Satellite-11 (GOES-11) rapid-scan atmospheric motion vectors, and NASA Quick Scatterometer (QuikSCAT) near-surface wind data collected during NASA's Tropical Cloud Systems and Processes (TCSP) field experiment in July 2005 were assimilated into an advanced research version of the Weather Research and Forecasting (WRF) model using its three-dimensional variational data assimilation (3DVAR) system. The impacts of the mesoscale data assimilation on WRF numerical simulation of Tropical Storms Cindy and Gert (2005) near landfall are examined. Sensitivity of the forecasts to the assimilation of each single data type is investigated. Specifically, different 3DVAR strategies with different analysis update cycles and resolutions are compared in order to identify the better methodology for assimilating the data from research aircraft and satellite for tropical cyclone study.

The results presented herein indicate the following. 1) Assimilation of dropwindsonde and satellite wind data into the WRF model improves the forecasts of the two tropical storms up to the landfall time. The QuikSCAT wind information is very important for improving the storm track forecast, whereas the dropwindsonde and GOES-11 wind data are also necessary for improved forecasts of intensity and precipitation. 2) Data assimilation also improves the quantitative precipitation forecasts (QPFs) near landfall of the tropical storms. 3) A 1-h rapid-update analysis cycle at high resolution $(9 \mathrm{~km})$ provides more accurate tropical cyclone forecasts than a regular 6-h analysis cycle at coarse $(27 \mathrm{~km})$ resolution. The high-resolution rapidly updated 3DVAR analysis cycle might be a practical way to assimilate the data collected from tropical cyclone field experiments.
\end{abstract}

\section{Introduction}

As witnessed in recent years, the social, ecological, and economic impacts of tropical cyclones can be devastating. Strong wind, heavy rain, and storm surge associated with tropical cyclones may cause flooding, soil

\footnotetext{
Corresponding author address: Dr. Zhaoxia Pu, Dept. of Meteorology, University of Utah, 135 S 1460 E, Rm. 819, Salt Lake City, UT 84112.

E-mail: zhaoxia.pu@utah.edu
}

DOI: $10.1175 / 2007$ WAF2007006.1

(C) 2008 American Meteorological Society erosion, and landslides, even far away from the landfall location, resulting in numerous human casualties and enormous property damage. Accurate forecasts of tropical cyclones and their associated precipitation have been listed as a high-priority research area by the U.S. Weather Research Program (e.g., Elsberry and Marks 1999).

Tropical cyclones originate over the ocean, where conventional meteorological observations tend to be sparse on a daily routine basis. Due to a lack of data, deficiencies in model initial conditions can lead to in- 
accurate forecasts of tropical cyclones. Our knowledge of the physics processes that control tropical cyclone evolution is also limited. Thus, the forecasting of tropical cyclone track and intensity remains a challenging problem for those making numerical weather predictions. Owing to the improvement of large-scale forecast models and data assimilation techniques, and also to the use of satellite and aircraft reconnaissance observations, tropical cyclone track forecasts have improved significantly during the last two decades. (Official error trends are documented online at http://www.nhc.noaa. gov/verification.) For instance, National Oceanic and Atmospheric Administration (NOAA) synoptic surveillance missions are very useful in improving individual tropical cyclone track forecasts (Franklin and DeMaria 1992; Franklin et al. 1993; Burpee et al. 1996; Aberson 2002; Aberson and Sampson 2003; Aberson and Etherton 2006). Satellite-derived observations have also improved tropical cyclone analyses and forecasts (e.g., Velden et al. 1992; Velden et al. 1998; Pu et al. 2002; Pu and Tao 2004; Zhu et al. 2002; Hou et al. 2004, Chen 2007). However, relatively little progress has been made in hurricane intensity forecasts (Houze et al. 2006). In addition, only minor attention (Rogers et al. 2003) has been given to improving tropical cyclone quantitative precipitation forecasts (QPFs).

To better understand tropical cyclone structure and intensity change, field experiments, such as the annual NOAA Hurricane Field Program, the National Aeronautics and Space Administration (NASA) Convective and Moisture Experiment (CAMEX; Kakar et al. 2006), and the Hurricane Rainband and Intensity Change Experiment in 2005 (RAINEX; Houze et al. 2006), have been conducted to collect data during intensive observing periods. During July 2005, NASA, in collaboration with NOAA, executed the Tropical Cloud Systems and Process (TCSP) field experiment (Halverson et al. 2007) based in Costa Rica. The goal was to improve the understanding of tropical cyclogenesis and intensity change. During TCSP, in situ dropwindsondes from the NOAA P-3 aircraft and many types of special remotely sensed datasets were collected along with regular satellite and aircraft reconnaissance and surveillance data [such as dropwindsonde data from the NOAA Gulfstream-IV (G-IV), P-3s, and the U.S. Air Force C-130 aircraft]. With routinely available satellite data, such as those from the NOAA Geostationary Operational Environmental Satellite (GOES), NASA Quick Scatterometer (QuikSCAT), and the Tropical Rainfall Measuring Mission (TRMM) satellite, TCSP not only offered an opportunity to study tropical cyclone development in detail, but also to study the impact of remotely sensed and in situ data on mesoscale forecasts of tropical cyclones.

The goal of the study is to assess the potential for improving high-resolution numerical forecasts of tropical cyclones. Specifically, according to $\mathrm{Pu}$ and Braun (2001) and Wu et al. (2006), who used tropical cyclone bogus vortices, wind information is important for tropical cyclone initialization and prediction. Therefore, the main focus of this study is to incorporate satellitederived wind information with in situ dropwindsonde data into a mesoscale model with the aim of producing the best possible analyses and forecasts. In particular, the impact of dropwindsonde data, GOES-11 rapidscan atmospheric motion vectors (AMVs), and QuikSCAT near-surface wind observations gathered during TCSP on mesoscale model forecasts of tropical cyclones is demonstrated. Two tropical cyclones that occurred during TCSP, Cindy and Gert, near their respective landfalls, are chosen for the study. The impacts of the data on forecasts of track, intensity, and quantitative precipitation forecasts (QPFs) through improved strategies for mesoscale data assimilation are explored.

The Advanced Research Weather Research and Forecasting (ARW, hereafter WRF) model and its three-dimensional variational data assimilation (3DVAR) system are used. A brief description of the two tropical cyclones is given in section 2. The data sources for the experiments are summarized in section 3. The WRF and its 3DVAR system, and the design of the data assimilation experiments, are introduced in section 4. The sensitivity to the assimilation of each data type and all data to the forecast of Tropical Storm Gert is examined in section 5. The impact of the data assimilation on the forecast of Tropical Storm Cindy is discussed in section 6. Summary and conclusions are presented in section 7 .

\section{Overview of Tropical Storms Cindy and Gert (2005)}

The 2005 Atlantic hurricane season (Beven et al. 2008) is notable for having the most named storms in a single season (28). Five storms, including three hurricanes (Cindy, Dennis, and Emily), were active in July during the TCSP field campaign. Cindy and Gert were chosen for study because TCSP aircraft data were collected during their approach toward landfall in the United States and Mexico, respectively.

According to the reports from the Tropical Prediction Center (information online at http://www.nhc. noaa.gov), Cindy formed from a vigorous tropical wave and developed into a tropical depression in the northwestern Caribbean Sea on 3 July. It reached tropical 


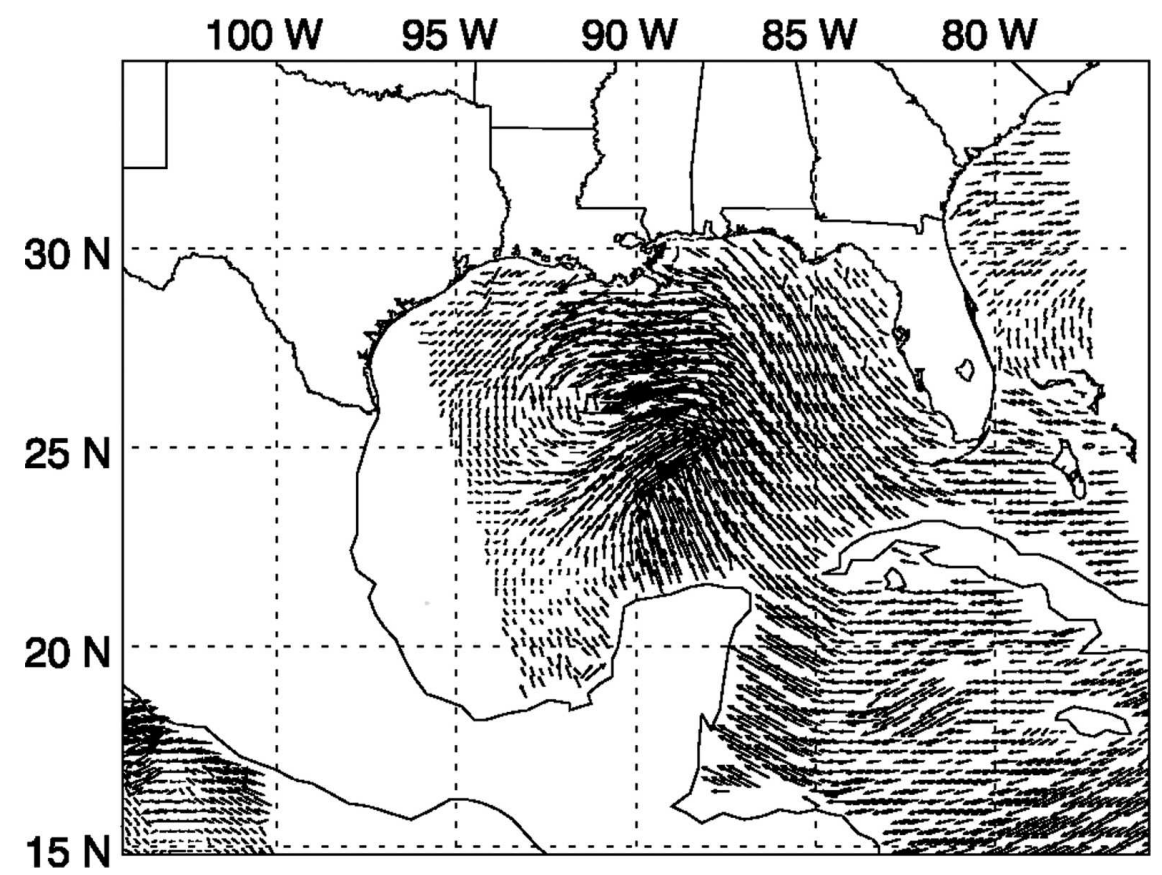

FIG. 1. QuikSCAT surface vector wind data at 1200 UTC 5 Jul 2005.

storm strength after exiting the Yucatán Peninsula on 5 July. The storm then headed to the north across the Gulf of Mexico and made landfall as a hurricane near Grand Isle, Louisiana, late on 6 July and again as a tropical storm near Ansley, Mississippi, a few hours later. The storm weakened over Mississippi and Alabama before evolving into an extratropical cyclone over the Carolinas on July 7. Heavy rainfall and flooding were the main threat from Cindy, with one death attributed to the storm.

Gert originated from a tropical wave that emerged off of the west coast of Africa on 10 July. It moved west-northwest over the Atlantic to the Lesser Antilles by 18 July. The southern part of the wave continued westward over the central and western Caribbean Sea and formed a low pressure area to the east of Chetumal, Mexico, on 22 July. The low moved west-northwestward and organized into a tropical depression at 1800 UTC 23 July 2005 in the Bay of Campeche. It developed into Tropical Storm Gert at 0600 UTC 24 July 2005, then continued to strengthen and made landfall to the north of Cabo Rojo, Mexico, at 0000 UTC 25 July 2005 with maximum sustained winds of $40 \mathrm{kt}$ (20 $\mathrm{m} \mathrm{s}^{-1}$ ) and a minimum central pressure of $1005 \mathrm{hPa}$. It then moved over central Mexico before dissipating on 25 July. Gert struck in roughly the same area that Hurricane Emily had impacted only a few days earlier and brought heavy rainfall there, causing flooding and landslides due to the already saturated land.

\section{Special observations collected during TCSP}

TCSP was an earth science research program sponsored by the NASA Science Mission Directorate. The field experiment was based out of the Juan Santamaría International Airport in San José, Costa Rica, and carried out during 1-28 July 2005. Scientists from NASA, NOAA, and the academic community were involved. During TCSP, a NOAA P-3 aircraft, directed by the Hurricane Research Division and Aircraft Operations Center, flew 18 coordinated missions with the NASA research aircraft, primarily to investigate developing tropical disturbances. With the availability of routine information from NASA Earth Observing System satellites such as QuikSCAT, TRMM, and Aqua, as well as special GOES-11 rapid-scan observations made available by NOAA/NESDIS, and operational NOAA G-IV aircraft surveillance data and U.S. Air Force C-130 reconnaissance data, TCSP provided a unique opportunity to incorporate high-resolution aircraft and satellite data in mesoscale numerical prediction studies of tropical cyclones.

QuikSCAT SeaWinds level-2B wind vectors derived from Wentz and Smith (1999) at approximately $25-\mathrm{km}$ resolution over only oceanic regions are used. A sample of the QuikSCAT wind vector fields available for the Cindy case at 1200 UTC 5 July 2005 is shown in Fig. 1.

During part of the TCSP period, GOES-11 was activated by NOAA/National Environmental Satellite, 

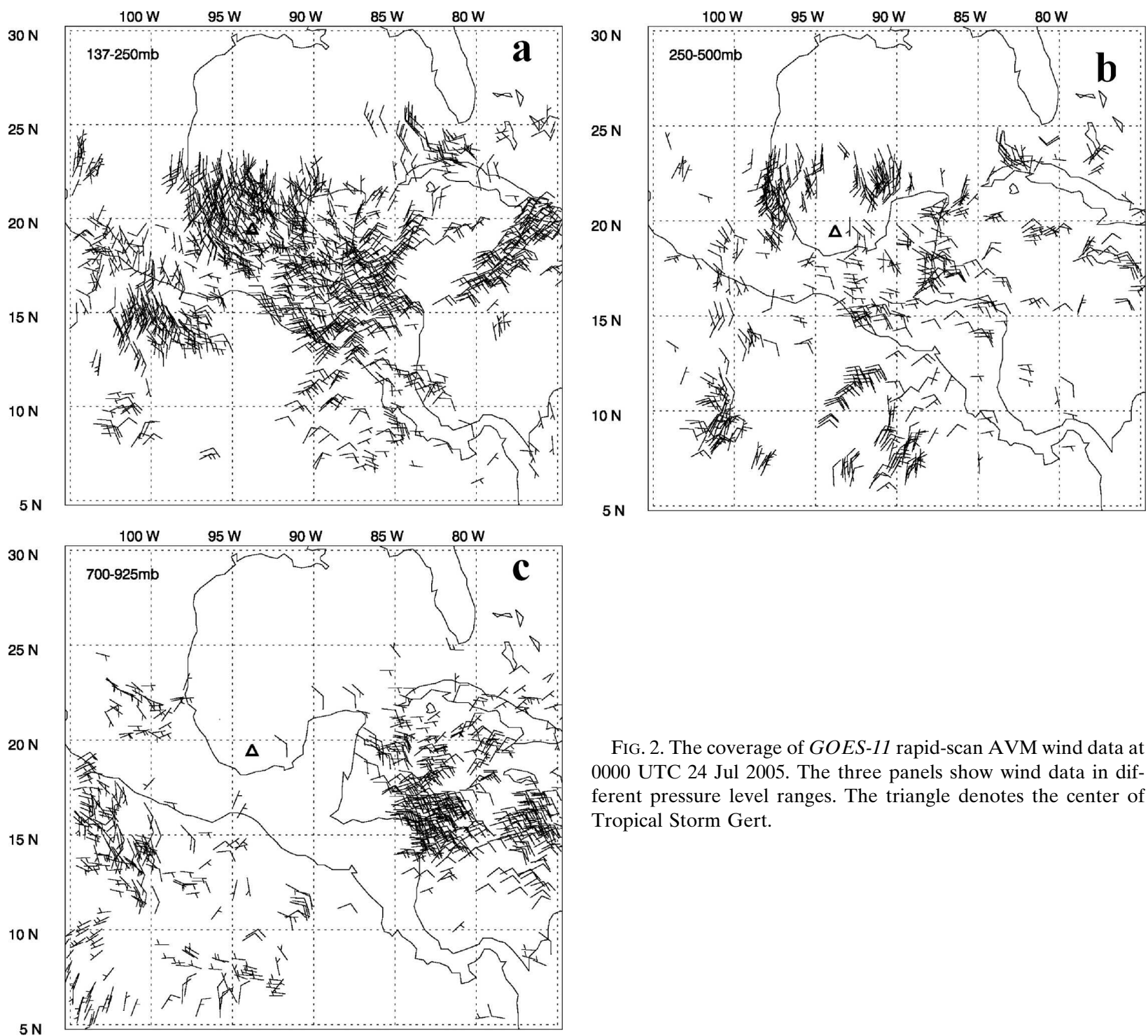

FIG. 2. The coverage of GOES-11 rapid-scan AVM wind data at 0000 UTC 24 Jul 2005. The three panels show wind data in different pressure level ranges. The triangle denotes the center of Tropical Storm Gert.

Data, and Information Service (NESDIS) to operate in rapid-scan mode, providing imagery at 5-min intervals over the Caribbean Sea, the eastern Pacific Ocean, and adjacent regions. From these data, the Cooperative Institute for Meteorological Satellite Studies (CIMSS) at the University of Wisconsin employed automated cloud-tracking algorithms (Velden et al. 1997) to produce high-density and high-quality AMVs over the domain (Velden et al. 2005). Figure 2 shows a sample of the GOES-11 AMV coverage at 0000 UTC 24 July 2005 near Tropical Storm Cindy. The data availability in different pressure ranges is marked in different panels; most of the GOES-11 AMVs are located between 100 and $250 \mathrm{hPa}$.

All available in situ dropsonde observations during the TCSP mission, including NOAA P-3 and opera-

tional NOAA G-IV aircraft surveillance data and U.S. Air Force C-130 reconnaissance data, are used in this study. The locations of these data are shown in Fig. 3.

\section{Description of the model, data assimilation system, and experimental design}

\section{a. WRF model and its 3DVAR system}

WRF is a recently developed, next-generation, mesoscale numerical weather prediction system featuring multiple dynamic cores designed to serve both operational forecast and research needs. It is based on an Eulerian solver for the fully compressible nonhydrostatic equations, cast in flux conservation form, using a mass (hydrostatic pressure) vertical coordinate. The solver uses a third-order Runge-Kutta time integration 

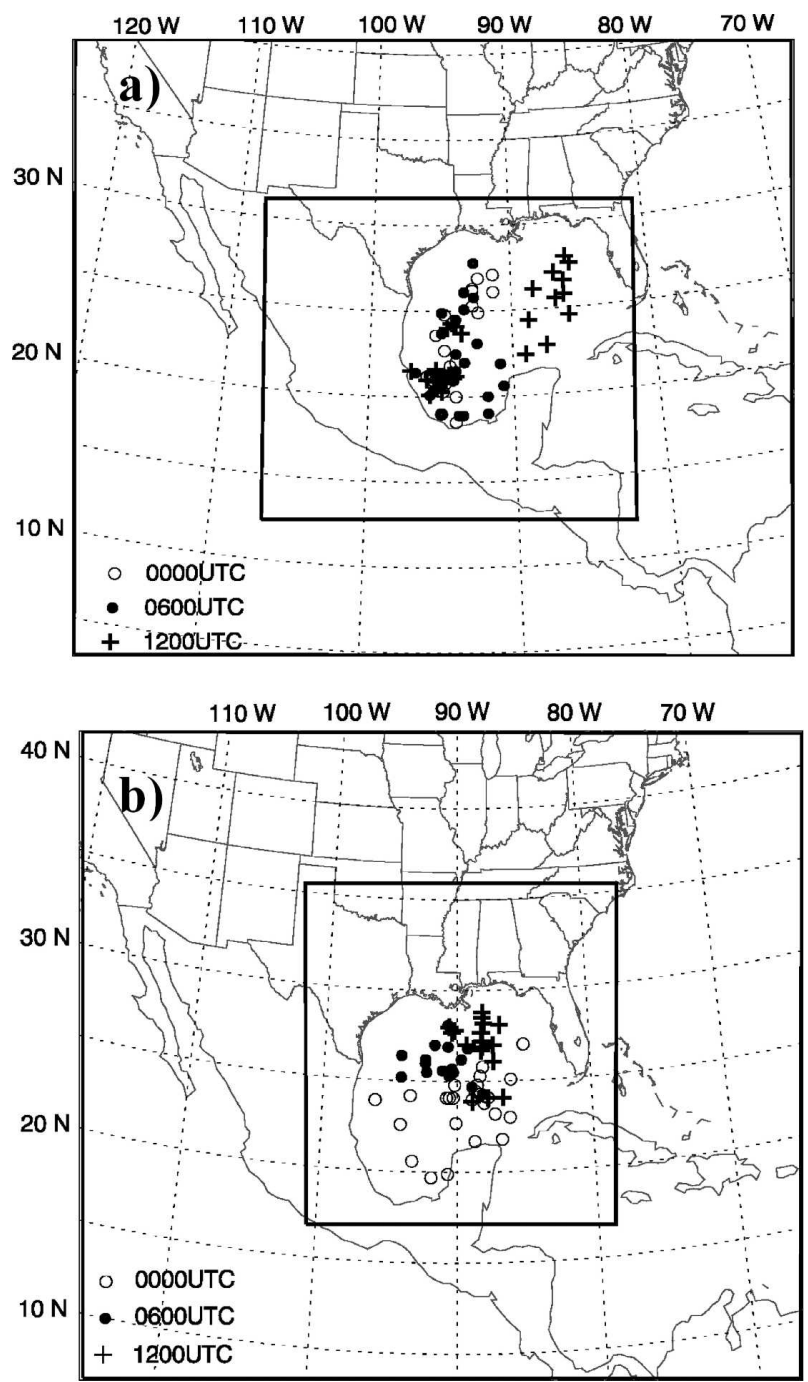

FIG. 3. Location of the model domains for (a) Topical Storm Gert and (b) Tropical Storm Cindy. The outer domain is the $27-\mathrm{km}$ grid and the inner domain is the nested, 9-km grid used in the forecast. The cross, triangle, and star symbols represent the dropwindsonde locations in the domain around 0000, 0600, and 1200 UTC, respectively.

scheme coupled with a split-explicit second-order time integration scheme for the acoustic and gravity wave modes. Fifth-order upwind-biased advection operations are used in the fully conservative flux divergence integration; second- to sixth-order schemes are run-time selectable. WRF has multiple physical options for cumulus, microphysics, planetary boundary layer, and radiation physical processes. Details of the model are provided in Skamarock et al. (2005).

Along with WRF, a three-dimensional variational data assimilation (3DVAR) system was developed based on the fifth-generation Pennsylvania State University-National Center for Atmospheric Research
TABLE 1. The dimension, grid space, and time step for each domain.

\begin{tabular}{lcccc}
\hline \hline Case & Domain & $\begin{array}{c}\text { Horizontal grid } \\
\text { dimensions }\end{array}$ & $\begin{array}{c}\text { Grid spacing } \\
(\mathrm{km})\end{array}$ & $\begin{array}{c}\text { Time } \\
\text { step (s) }\end{array}$ \\
\hline Cindy & A & $196 \times 156$ & 27 & 120 \\
& $\mathrm{~B}$ & $262 \times 235$ & 9 & 40 \\
Gert & $\mathrm{A}$ & $190 \times 150$ & 27 & 120 \\
& $\mathrm{~B}$ & $298 \times 235$ & 9 & 40 \\
\hline
\end{tabular}

Mesoscale Model (MM5) 3DVAR system (Barker et al. 2004a,b). Details of the 3DVAR method are provided in Barker et al. (2004a), Kalnay (2003), and Lorenc (1986).

For the experiments in this study, model physics options include the Betts-Miller-Janjić cumulus parameterization (Betts and Miller 1986), Ferrier microphysics scheme, Yonsei University (YSU) planetary boundary layer parameterization (Skamarock et al. 2005; Hong and Pan 1996), and the Rapid Radiative Transfer Model (RRTM; Mlawer et al. 1997) longwave and Dudhia shortwave atmospheric radiation (Dudhia 1989) schemes. A two-way interactive, two-level nested grid technique is employed to achieve the multiscale forecast. The outer domain resolution has $27-\mathrm{km}$ grid spacing and the inner domain resolution is $9 \mathrm{~km}$. The model vertical structure comprises $31 \sigma$ levels with the top of the model set at $50 \mathrm{hPa}$, where $\sigma=\left(p_{h}-p_{h t}\right) /$ $\left(p_{h s}-p_{h t}\right)$, while $p_{h}$ is the hydrostatic component of the pressure, and $p_{h s}$ and $p_{h t}$ refer to values of the pressure along the surface and top boundaries, respectively. The $\sigma$ levels are placed close together in the low levels (below $500 \mathrm{hPa}$ ) and are relatively coarsely spaced above. The model domains are shown in Fig. 3, and Table 1 gives the dimensions, grid spacing, and time step for each domain.

For the 3DVAR experiments, the background error covariance matrix B was estimated using the so-called NMC [for the National Meteorological Center, now known as the National Centers for Environmental Prediction (NCEP)] method (Parrish and Derber 1992; Wu et al. 2002; Barker et al. 2004a). The observational error covariance matrices, $\mathbf{O}_{\text {Quikscat }}, \mathbf{O}_{\text {Goes }}$, were treated as diagonal matrices with statistically determined variances of $25 \mathrm{~m}^{2} \mathrm{~s}^{-2}$ and $40 \mathrm{~m}^{2} \mathrm{~s}^{-2}$, respectively. Routine quality control was conducted before the data assimilation.

\section{b. Experimental design}

The data from NCEP global final analysis (FNL) on a $1.0^{\circ} \times 1.0^{\circ}$ grid were used to provide boundary conditions for numerical simulations. Instead of directly 
TABLE 2. Experimental design for Gert.

\begin{tabular}{|c|c|c|c|}
\hline Expt & $\begin{array}{c}\text { Type of } \\
\text { observations } \\
\text { assimilated }\end{array}$ & $\begin{array}{c}\text { Time of data } \\
\text { assimilated } \\
\text { (UTC, } 24 \\
\text { Jul 2005) }\end{array}$ & $\begin{array}{c}\text { Domain } \\
\text { of data } \\
\text { assimilation }\end{array}$ \\
\hline CTRL & N/A & N/A & N/A \\
\hline DROP & Dropwindsonde & $0000,0600,1200$ & A \\
\hline QS & QuikSCAT wind & 0000,1200 & A \\
\hline GOES & $G O E S-11$ wind & $0000,0600,1200$ & A \\
\hline \multirow[t]{3}{*}{ ALL-27 } & Dropwindsonde & $0000,0600,1200$ & A \\
\hline & QuikSCAT wind & 0000,1200 & \\
\hline & GOES-11 wind & $0000,0600,1200$ & \\
\hline RUC-27 & Same as ALL-27 & $\begin{array}{l}\text { 1-h analysis cycle } \\
\text { during } 0000-1200\end{array}$ & A \\
\hline RUC-9 & Same as ALL-27 & Same as ALL-27 & $\mathrm{B}$ \\
\hline
\end{tabular}

using NCEP FNL analysis for the first guess in the 3DVAR experiments, a WRF simulation, initialized by the WRF standard initialization process package using the NCEP FNL analysis, was first integrated $6 \mathrm{~h}$ to provide a first-guess field for 3DVAR data assimilation. The control forecast (CNTL) continued the simulation without the additional data assimilated.

To test the impact of model resolution on data assimilation, the data assimilation experiments are conducted for the two domains separately. However, all of the forecasts are run using both domains. For the experiments with data assimilation performed on the outer domain, the initial condition for the 9-km gridspacing domain is derived from the $27-\mathrm{km}$ spacing using a monotonic interpolation scheme based upon Smolarkiewicz and Grell (1992). All figures present results from the 9-km grid-spacing domain.

As we would like to investigate the impact of the aircraft and satellite data on the forecast of the two tropical cyclones near landfall, the cycling 3DVAR experiments are conducted with three consecutive 6-h data assimilation windows from 0000 UTC 5 July to 1200 UTC 5 July for Cindy and from 0000 UTC 24 July to 1200 UTC 24 July for Gert, during the periods of intensive observations. Forecasts are then run through $24 \mathrm{~h}$ for Gert and $36 \mathrm{~h}$ for Cindy to forecast the landfall of each storm. U.S. Air Force and NOAA G-IV dropwindsonde data are available near 0000, 0600, and 1200 UTC 5 July 2005 for Cindy, whereas QuikSCAT surface wind data are available only near 1200 UTC 5 July 2005 (no GOES-11 rapid-scan AMVs are available). For Gert, U.S. Air Force and NOAA P-3 dropwindsonde, GOES-11 AMV, and QuikSCAT surface winds are all available at or near 0000 and 1200 UTC July 24, whereas only the dropwindsonde and AMV data are available near 0600 UTC 24 July (Table 2).

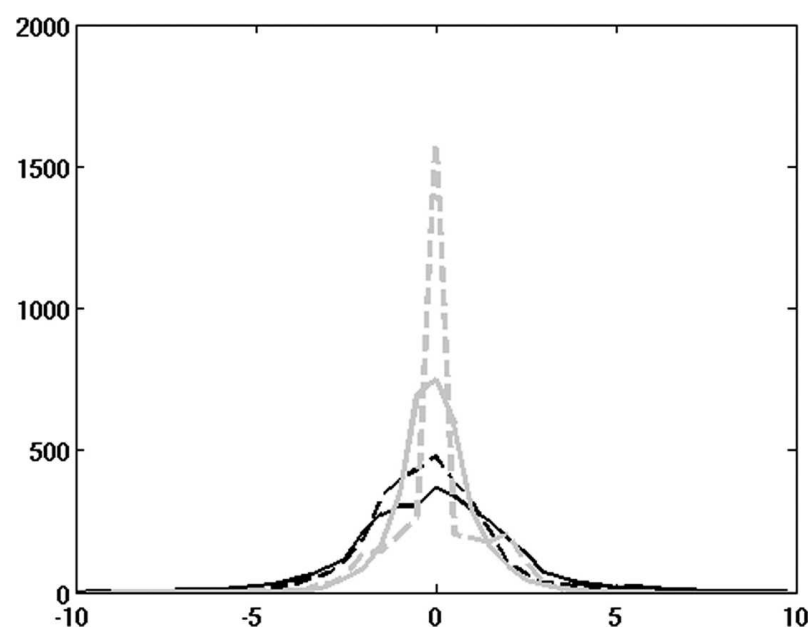

FIG. 4. Histogram of wind speed departure from observations for WRF first-guess winds ( $o-b$; solid lines) and WRF 3DVAR analyzed winds $(o-a$; dash lines). The departures are calculated for QuikSCAT surface wind data in the WRF domain from the first-guess and analysis fields at both 0000 and 1200 UTC $24 \mathrm{Jul}$ 2005. The horizontal axis denotes the wind speed departure $\left(\mathrm{m} \mathrm{s}^{-1}\right)$ and the vertical axis represents the number of observations. The black lines indicate the results from assimilation of QuikSCAT only, and the gray lines represent the results from assimilation of all three types [QuickSCAT (QS), dropwindsondes, and GOES-11 AMVs].

\section{Data assimilation and forecasts for Tropical Storm Gert}

\section{a. The impact of different observation types on initial analyses}

Since dropwindsonde data, QuikSCAT winds and GOES rapid-scan AMVs are all available during Gert, a series of model runs are conducted to examine the

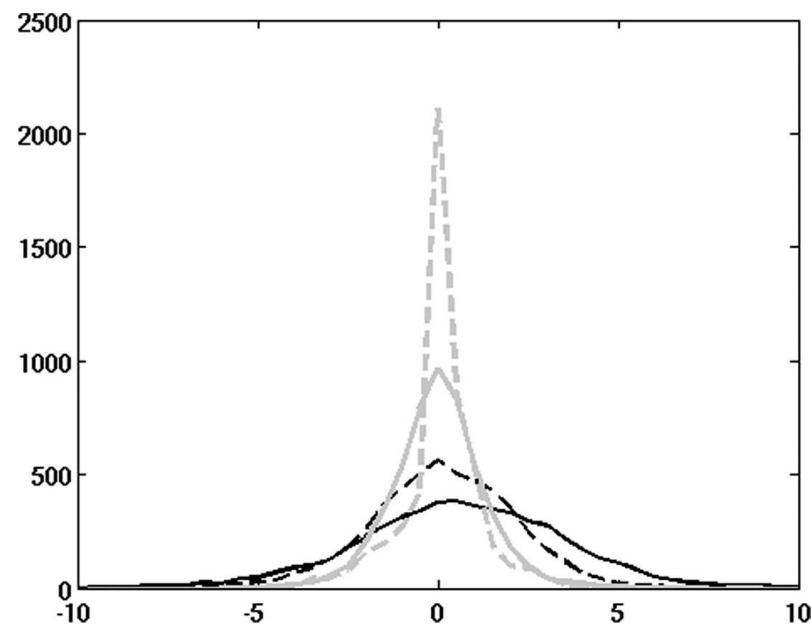

FIG. 5. Same as in Fig. 4 except the departures are for GOES-11 wind data in the WRF domain at 0000, 0600, and 1200 UTC $24 \mathrm{Jul}$ 2005. 

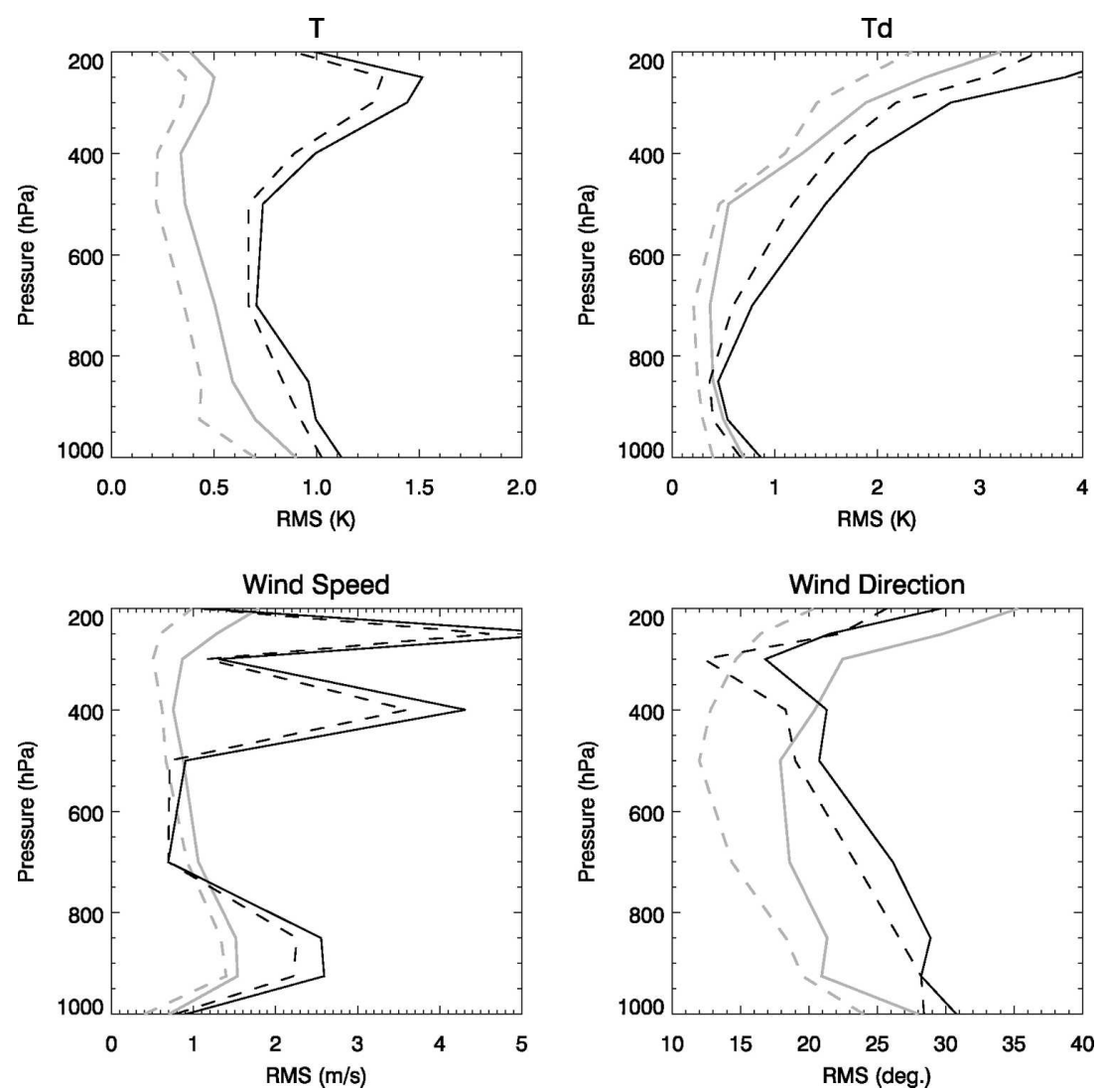

FIG. 6. RMS fit of temperature (K), dewpoint temperature (K), and wind speed $\left(\mathrm{m} \mathrm{s}^{-1}\right)$ and direction $\left(^{\circ}\right)$ against the dropwindsonde data for the analysis field at 0000,0600 , and 1200 UTC 24 Jul 2005. Dashed line is for the data assimilation experiment DROP and the solid line for the CTRL (first guess). The black lines indicate the assimilation of dropwindsonde data only and the gray color lines represent the assimilation of all three types (QuickSCAT, dropwindsondes, and GOES-11 AMVs).

impact of each individual data type on the initial analyses and subsequent forecasts. A set of data assimilation experiments is performed on the model outer-domain (27-km resolution) although all forecasts are from 9-km grid. The CTRL and experiments with data assimilation are compared. The detailed experimental design is listed in Table 2.

To get an idea of the impact from each data type on initial analysis and also to show how other data affect the assimilation of the individual data type when all three types data are assimilated, the statistics of initial conditions fit to each type of the observations are compared in different experiments.

\section{1) QUikSCAT NEAR-SURFACE WINDS}

A total of 3117 QuikSCAT vector wind observations were assimilated at 0000 UTC and 1200 UTC 24 July 2005 . The wind speed differences between observations and the first guess $(o-b)$ and the differences between the observations and the analysis $(o-a)$ indicate that the difference range is reduced from $[-10.3,14.4] \mathrm{m} \mathrm{s}^{-1}$ in $o-b$ to $[-5.4,7.5] \mathrm{m} \mathrm{s}^{-1}$ in $o-a$ (Fig. 4, black curves). Specifically, there are about 363 observations in which the differences fall in the $\pm 0.25 \mathrm{~m} \mathrm{~s}^{-1}$ range in $o-b$, whereas that number rose to nearly 749 after the data assimilation. The root-mean square (RMS) fit is reduced from $3.0 \mathrm{~m} \mathrm{~s}^{-1}$ in $o-b$ to $1.4 \mathrm{~m} \mathrm{~s}^{-1}$ in $o-a$. Overall, the data assimilation produced analyses that fit the QuikSCAT observations well.

\section{2) GOES-11 RAPID-SCAN AMVS}

A total of 5216 AMVs were assimilated at 0000, 0600, and 1200 UTC 24 July 2005. The difference between the analysis and the observations $(o-a)$, shown in Fig. 5 (black curves) with a difference range of $[-4.7,6.3]$ $\mathrm{m} \mathrm{s}^{-1}$, is reduced significantly compared with the difference between the first guess and the observations $(o-b)$ with a difference range of $[-12.6,16.4] \mathrm{m} \mathrm{s}^{-1}$. 


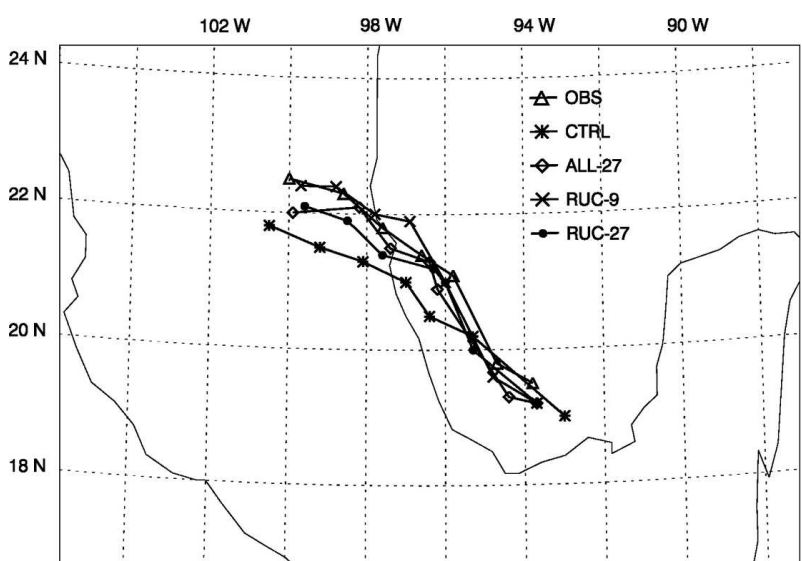

FIG. 7. Forecast Tropical Storm Gert's track during 0000 UTC 24 Jul-1200 UTC $25 \mathrm{Jul} 2005$, from the CTRL and experiments (a) ALL-27, (b) RUC-27, and (c) RUC-9. The forecast tracks are compared with the observed track. Center locations along the tracks are indicated every $6 \mathrm{~h}$. All forecasts shown in this paper are from domain B (9-km grid-spacing resolution).

There are about 385 observations where the differences fall in the $\pm 0.25 \mathrm{~m} \mathrm{~s}^{-1}$ in $o-b$, whereas that number rose to nearly 964 after data assimilation.

\section{3) DROPWINDSONDE DATA}

More than 50 dropwindsonde profiles (Fig. 3) with thousands of individual records of wind vector, temperature, moisture, and height at different pressure levels were assimilated at 0000, 0600, and 1200 UTC 24 July 2005. The black curves in Fig. 6 compare the RMS of the first-guess fit and the analysis fit to the observations for 0000,0600 , and 1200 UTC. The analysis with dropwindsonde data assimilated fits the observations more closely when compared to the first guess.

\section{4) All data}

A final experiment includes the assimilation of all three data types (GOES, QuikSCAT, and dropwindsonde data). When all three data types are assimilated during the 12-h data assimilation period, the analysis generally fits each type of the data better than the case when only one type of observations is assimilated (gray curves in Figs. 4-6). Specifically, the numbers of observations with the differences that fall in the $\pm 0.25 \mathrm{~m} \mathrm{~s}^{-1}$ range in $o-a$ are increased to 1582 for QuikSCAT observations (Fig. 4) and 2109 for GOES-11 wind observations (Fig. 5), respectively. The RMSs of the analysis fit to the dropwindsonde observations are also significantly improved in most of the cases (Fig. 6). Overall, the results indicate that assimilation of all three data types together improves the fit of the initial analysis to each and every type of the data.

\section{b. Forecast impact and sensitivity to observation type}

\section{1) STORM TRACK}

Figure 7 shows the tracks produced by different experiments during the period between 0000 UTC 24 July and 1800 UTC 25 July 2005. Note that the forecasts shown in Fig. 7 (also Figs. 8, 9, 13, 17, and 18) include the first 12-h analysis period. The track errors from each experiment are shown in Fig. 8. The storm track has been improved in all forecasts with data assimilation. When all data are assimilated into the model

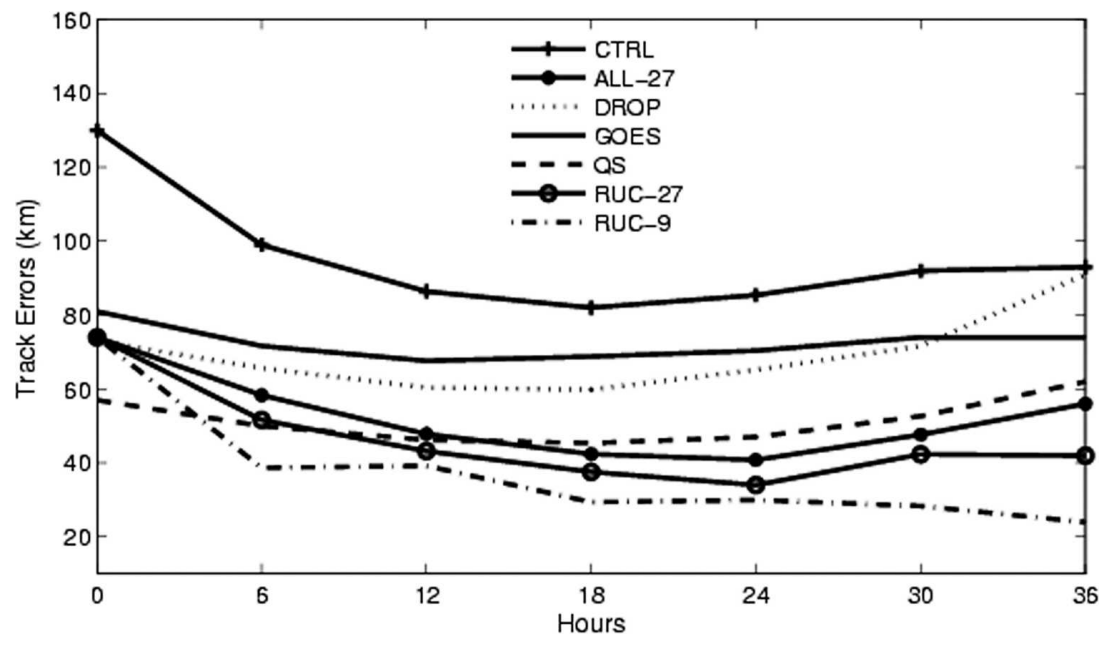

FIG. 8. Time series (at 6-h intervals) of forecast track errors $(\mathrm{km})$, which are defined as the distances between the forecast storm centers and the observed positions, for all forecasts during 0000 UTC 24 Jul-1200 UTC 25 Jul 2005. 

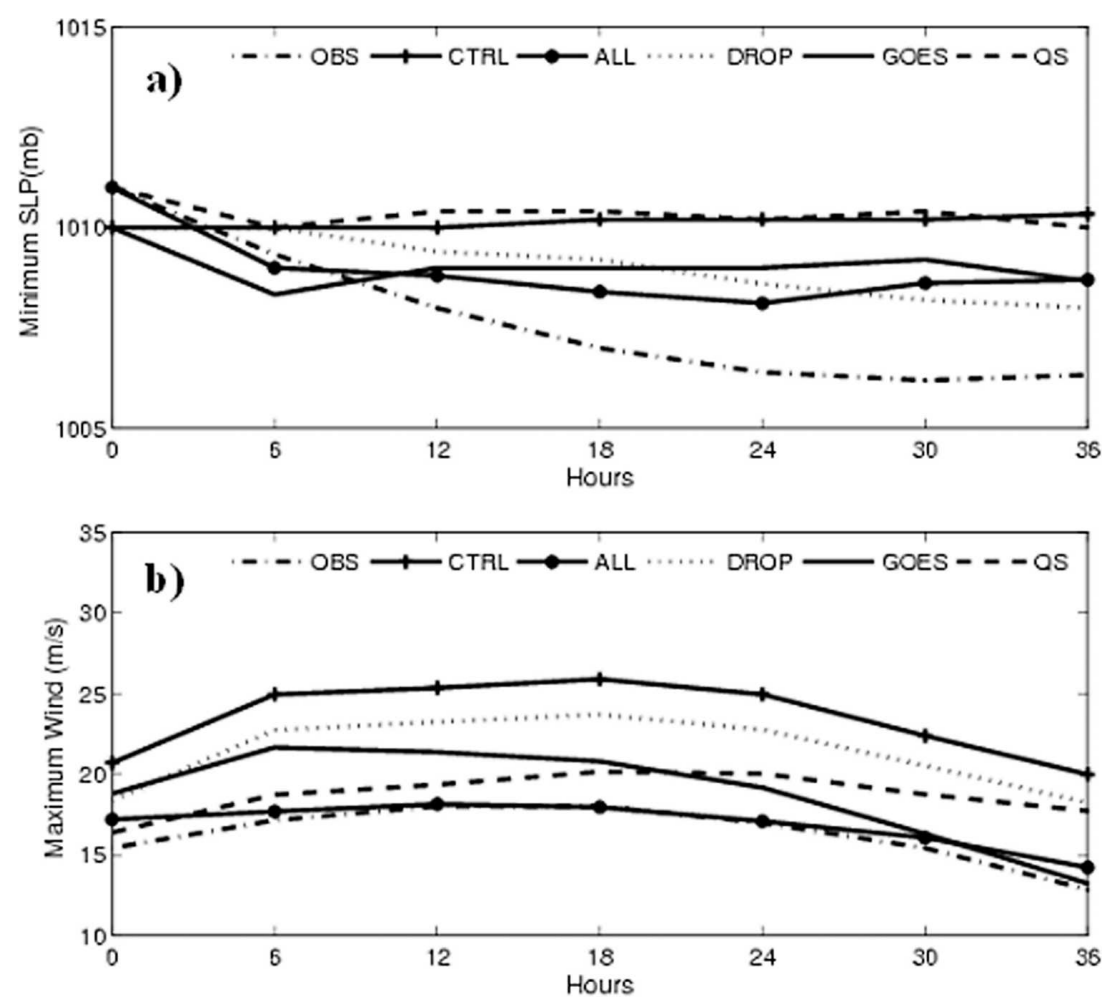

FIG. 9. Time series (at 6-h intervals) of (a) minimum sea level pressure (hPa) and (b) maximum winds $\left(\mathrm{m} \mathrm{s}^{-1}\right)$ at the surface $(10 \mathrm{~m})$ during 0000 UTC 24 Jul-1200 UTC 25 Jul 2005.

(ALL-27), the forecast landfall location and time are superior to that produced by the CTRL (Fig. 7) and yield the largest improvement $(\sim 50 \%)$ for most forecast times (Figs. 7 and 8). The CTRL storm made landfall almost $3 \mathrm{~h}$ earlier than observed about $75 \mathrm{~km}$ southwest of the verifying location. With assimilation of all data (ALL-27), the landfall time error is about $0.5 \mathrm{~h}$, and the forecast landfall location is about $40 \mathrm{~km}$ from the actual location (Fig. 7). In regard to the individual data type assimilation, the QuikSCAT data show the most significant impact on the forecast track (Fig. 8).

\section{2) INTENSITY}

Figure 9 compares storm intensity forecasts in terms of both minimum sea level pressure and maximum surface wind speed. Similar to the track forecasts, the best forecasts are produced by assimilating all three data types into the model. With assimilation of QuikSCAT data only, the model reproduces a better maximum near-surface wind forecast but slightly worse minimum central sea level pressure than the CTRL. Assimilation of GOES wind and dropwindsonde data both result in positive impacts on the minimum sea level pressure and maximum surface wind speed forecasts. The dropwindsonde data appear to be more beneficial to the mini- mum central sea level pressure forecasts, whereas the GOES wind data produce more positive impacts on the maximum surface wind speed forecasts.

\section{3) Precipitation}

Figure 10 shows the precipitation forecasts from the different experiments, compared with the estimated rainfall rate derived from the TRMM Microwave Imager (TMI) and infrared (IR) data at 1435 UTC 24 July 2005. The observed precipitation distribution (Fig. 10a; courtesy of Naval Research Laboratory) includes two major rainbands on the east and north sides of the tropical storm over the ocean, and a precipitation maximum in the southeast quadrant of the storm near the coast of Mexico. The CTRL produces a fairly realistic precipitation structure to the north of the storm (Fig. $10 \mathrm{~b}$ ), but misses the major maximum to the southeast. With the assimilation of QuikSCAT data only, the model reproduces a somewhat realistic rainband structure to the north of the storm, but misses the major rainbands on the east side (Fig. 10c). The major rainfall maximum near the coast is also missed. The forecast with GOES-11 wind data assimilation is similar to that of QuikSCAT and generates a reasonable rainband structure on the north side of the storm, but also misses 

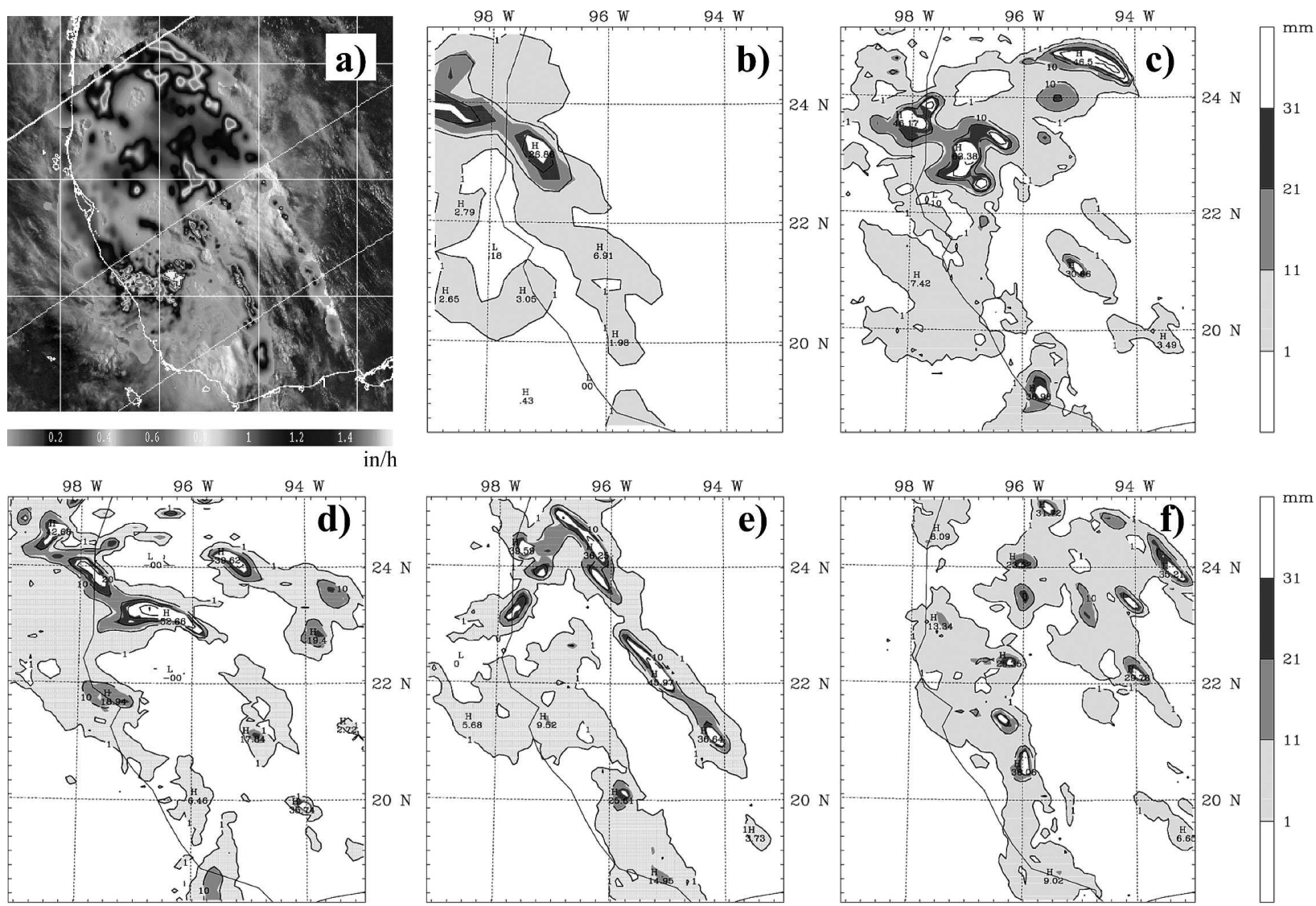

FIG. 10. Hourly rainfall rate (a) derived from IR and TMI satellite data at 1435 UTC 24 Jul 2005 and forecasted from experiments (b) CTRL, (c) QS, (d) GOES, (e) DROP, and (f) ALL-27, valid at 1430 UTC 24 Jul 2005.

the maximum precipitation center near the coastline (Fig. 10d). The dropwindsonde data assimilation forecasts capture the rainfall features near the coastline of Mexico well. Strong rainbands on the east and north sides are also reproduced, although some details are still missing (Fig. 10e). The most successful results of the maximum rainfall feature to the southeast of the storm are obtained with all three data types assimilated into the model (Fig. 10f).

The differences in precipitation structures from forecasts with the various data types assimilated may be attributed to the data impact on the overall convergent-divergent flow of the vortex and vertical wind shear in the storm environment. Figure 11 shows the averaged divergence profiles over the storm area (a circled region with radius of $250 \mathrm{~km}$ from the storm center) at 1200 UTC 24 July 2005, the end of the data assimilation period. Figure 11 indicates that all data assimilation experiments result in increases of low-level convergence and upper-level divergence (except for GOES, which does not increase low-level convergence) associated with the storm, although the detailed impact from each data type tends to be different. Specifically, compared with the CTRL, assimilation of the QuikSCAT and GOES wind data increases the integrated low- to midlevel convergence, extending it upward to about the 400-mb level. The dropwindsonde data cause a significant increase in both low-level convergence and upper-level divergence. With all three data types assimilated into the model, the low-level convergence and upper-level divergence both are moderately increased.

Figure 12 shows hodographs of the environmental flow between 850 and $200 \mathrm{hPa}$ in a box with $250 \mathrm{~km}$ on a side centered on the storm at 1200 UTC 24 July 2005. Significant differences in vertical wind shear are found in different experiments. Assimilation of GOES wind data caused the largest change in vertical wind shear. Specifically, the shear is southwesterly in all cases except GOES. In addition, magnitudes of the vertical wind shear are also different in different experiments. Rogers et al. (2003) indicated that the vertical wind shear could govern the azimuthal variation of rainfall. In addition, it has been well accepted that the environmental wind shear in the low to middle troposphere is one of the key factors that influences the motion and intensity of tropical cyclones (e.g., Zhang and Kieu 


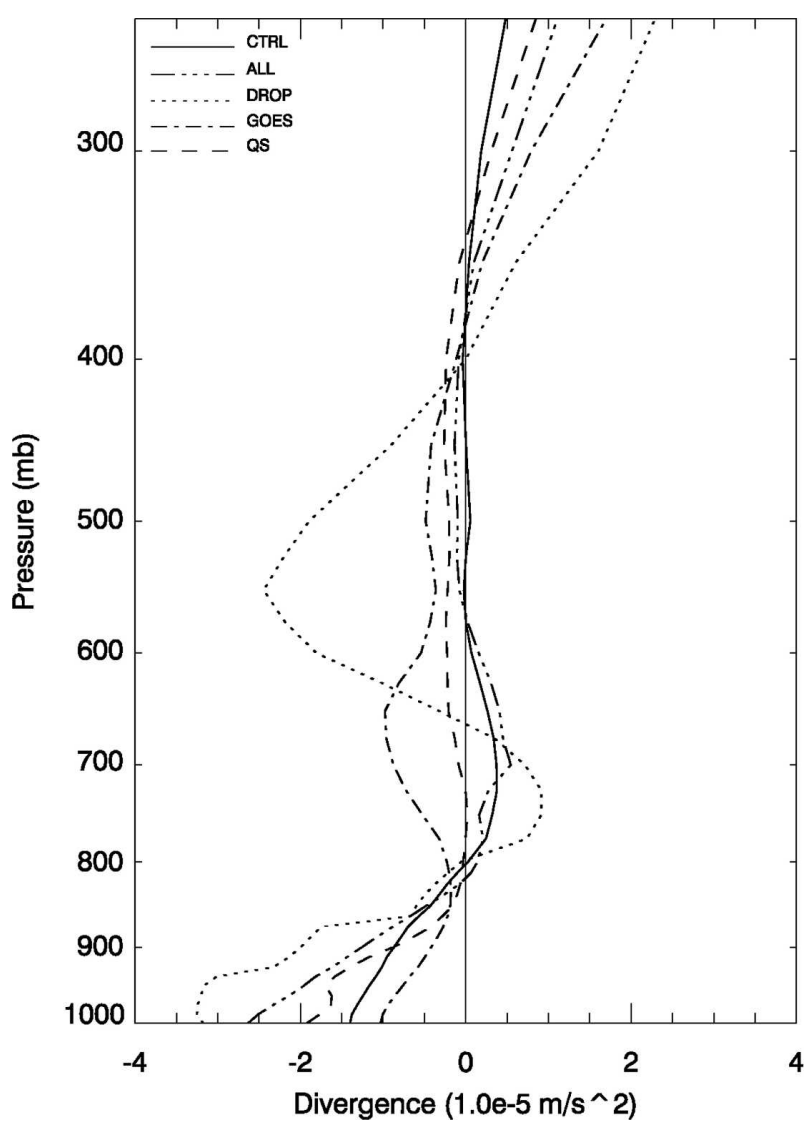

FIG. 11. Averaged divergence profiles over the area with radius of $250 \mathrm{~km}$ around the storm center at 1200 UTC $24 \mathrm{Jul} 2005$. The vertical axis denotes the tropospheric pressure levels. The horizontal axis represents the magnitudes of the divergence $\left(10^{-5}\right.$ $\mathrm{m} \mathrm{s}^{-2}$ ).

2006; Frank and Ritchie 1999). Therefore, the changes in the environmental wind shears from different experiments explain at least partially why assimilation of additional data into the model resulted in a significant impact on the track, intensity, and precipitation structures of Gert.

\section{c. Regular 6-h data assimilation cycle versus 1-h rapid updated cycle (RUC)}

In all of the above experiments, the analyses were generated from regular 6-h data assimilation cycles. However, for most of the special nonconventional observations, the exact observing time is scattered within the cutoff window. Therefore, there is good reason to assimilate the data with 3DVAR in a rapid update cycle (RUC) with a short cutoff window. Thus, a set of experiments using a 1-h RUC data assimilation instead of a 6-h data assimilation cycle was performed. All three types of the data were assimilated every hour (i.e., 1-h analysis cycle) with a cutoff window of [ $-0.5 \mathrm{~h}, 0.5 \mathrm{~h}]$ during the first 12 -h forecast period. Figure 13 compares the variation of the storm intensity in terms of both minimum sea level pressure and maximum surface wind speed, showing a slight impact on the intensity forecast from the RUC. This small impact in the intensity forecast is mainly attributed to the weak storm intensity and relatively small intensity errors in the CTRL for Gert, and partly it is also due to the fact that the intensity of Gert barely changed during this period. However, when comparing the track errors generated from the RUC analysis with those from the regular analysis (Figs. 7 and 8), the differences are quite significant, indicating an obvious benefit to the track forecast from the RUC analyses.

\section{d. Data assimilation at fine resolution (9-km grid spacing) and its impact on forecasts}

So far, all data assimilation experiments described have been conducted on the $27-\mathrm{km}$ resolution domain, although forecasts were performed on the nested domains with 9-km grid spacing. To test the sensitivity of our forecasts to the data assimilation at fine resolution, the RUC data assimilation was performed using the model inner domain (9-km grid spacing). All of the

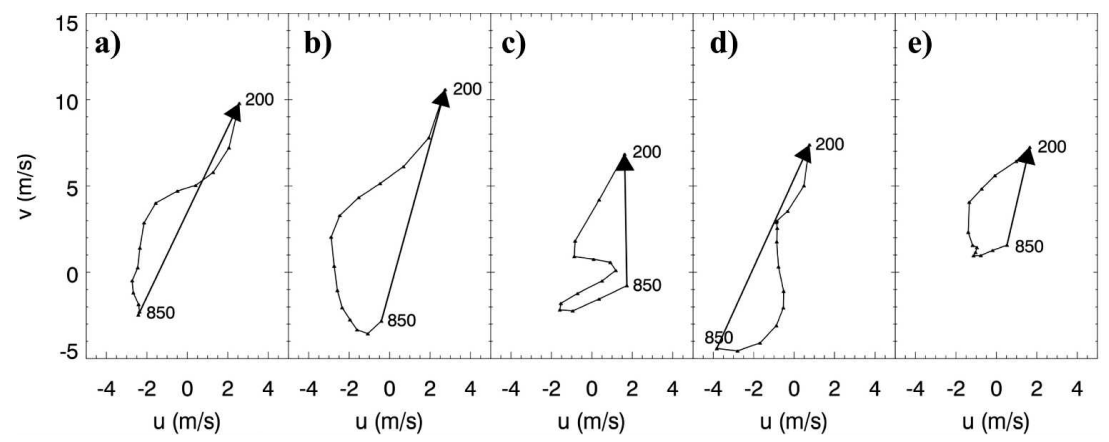

FIG. 12. Hodograph of the environmental winds between 850 and $200 \mathrm{hPa}$ in the vicinity of the vortex $\left(\mathrm{m} \mathrm{s}^{-1}\right)$ at $1200 \mathrm{UTC} 24 \mathrm{Jul} 2005$ for (a) CTRL, (b) QS, (c) GOES, (d) DROP, and (e) ALL-27. 

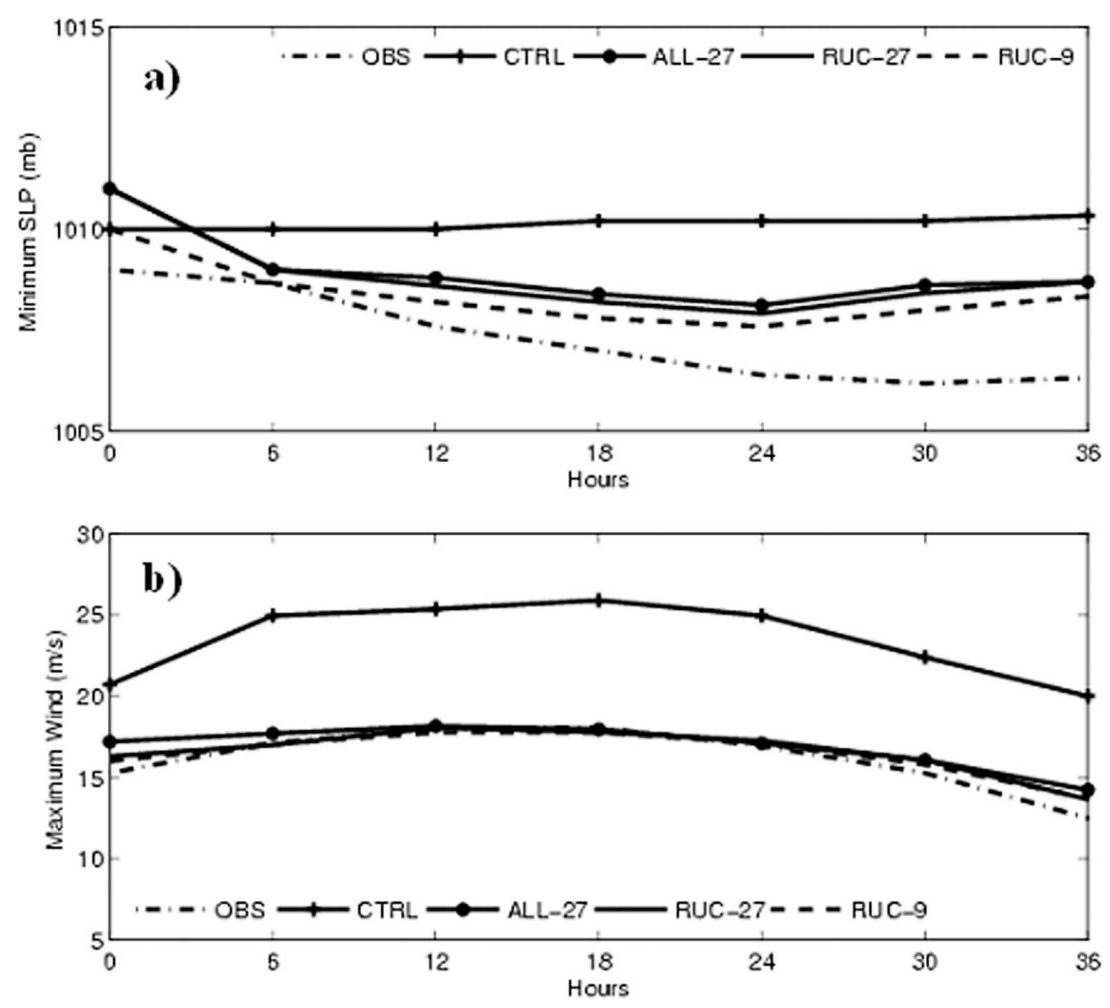

FIG. 13. Same as in Fig. 9 but for different experiments.

observations that reside within the inner domain were assimilated.

Compared with the $27-\mathrm{km}$ resolution RUC (RUC27) results, forecasts from the RUC analysis at $9 \mathrm{~km}$ (RUC-9) show additional improvement in track (Figs. 7 and 8) and intensity (Fig. 13) at most forecast times. The impact on precipitation structure is also quite significant. Figure 14 shows the forecast precipitation structure from RUC-9 at 1430 UTC 24 July 2005. Compared with Fig. 10a, Fig. 14 shows that almost all of the main observed features of the precipitation are nearly in the right location.

Better forecasts from RUC-9 could be attributed to the improved analysis after the data assimilation. Figure 15 compares the streamline and vector wind fields at 850 and $700 \mathrm{hPa}$ from the RUC-9 analysis and the CTRL at 0000 UTC 24 July 2005. Results of this comparison show that the RUC-9 analysis produced a strong convergent circulation with tropical storm features at both pressure levels, whereas the CTRL missed the strong convergent circulation associated with Gert.

\section{Tropical Storm Cindy forecasts}

Using a regular 6-h data assimilation cycle on a $27-$ $\mathrm{km}$ grid-spacing domain (ALL-27), dropwindsonde data from the U.S. Air Force and the G-IV were as- similated into the model at 0000, 0600, and 1200 UTC 5 July 2005 for Cindy, whereas the QuikSCAT wind data were assimilated into the model at 1200 UTC 5 July 2005 only. GOES-11 AMVs were not available for this case. In addition, in order to further test the benefit of the 1-h RUC simulation for tropical cyclone studies, a

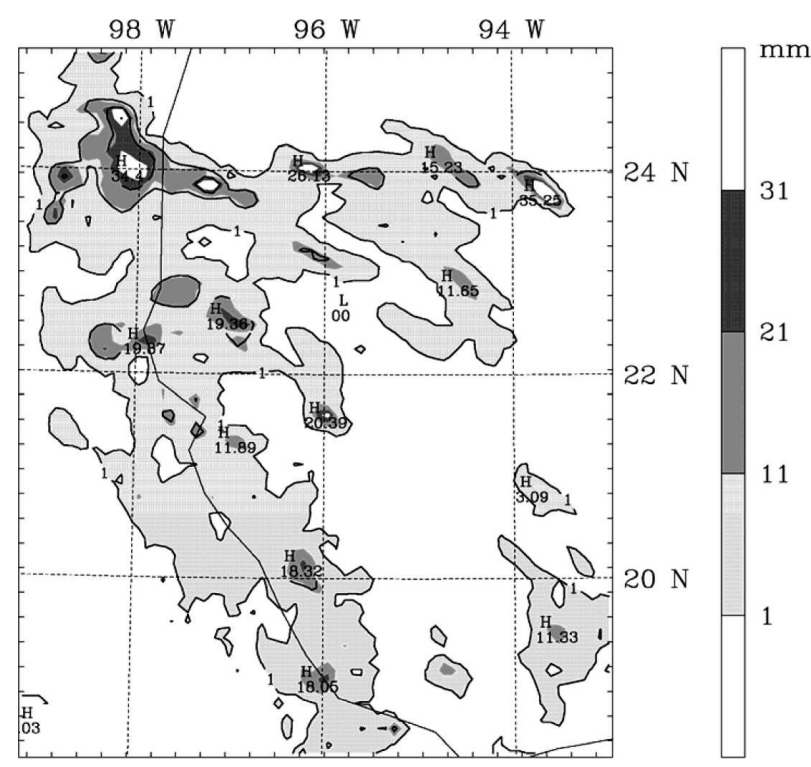

FIG. 14. Same as in Fig. 10 but for experiment RUC-9. 

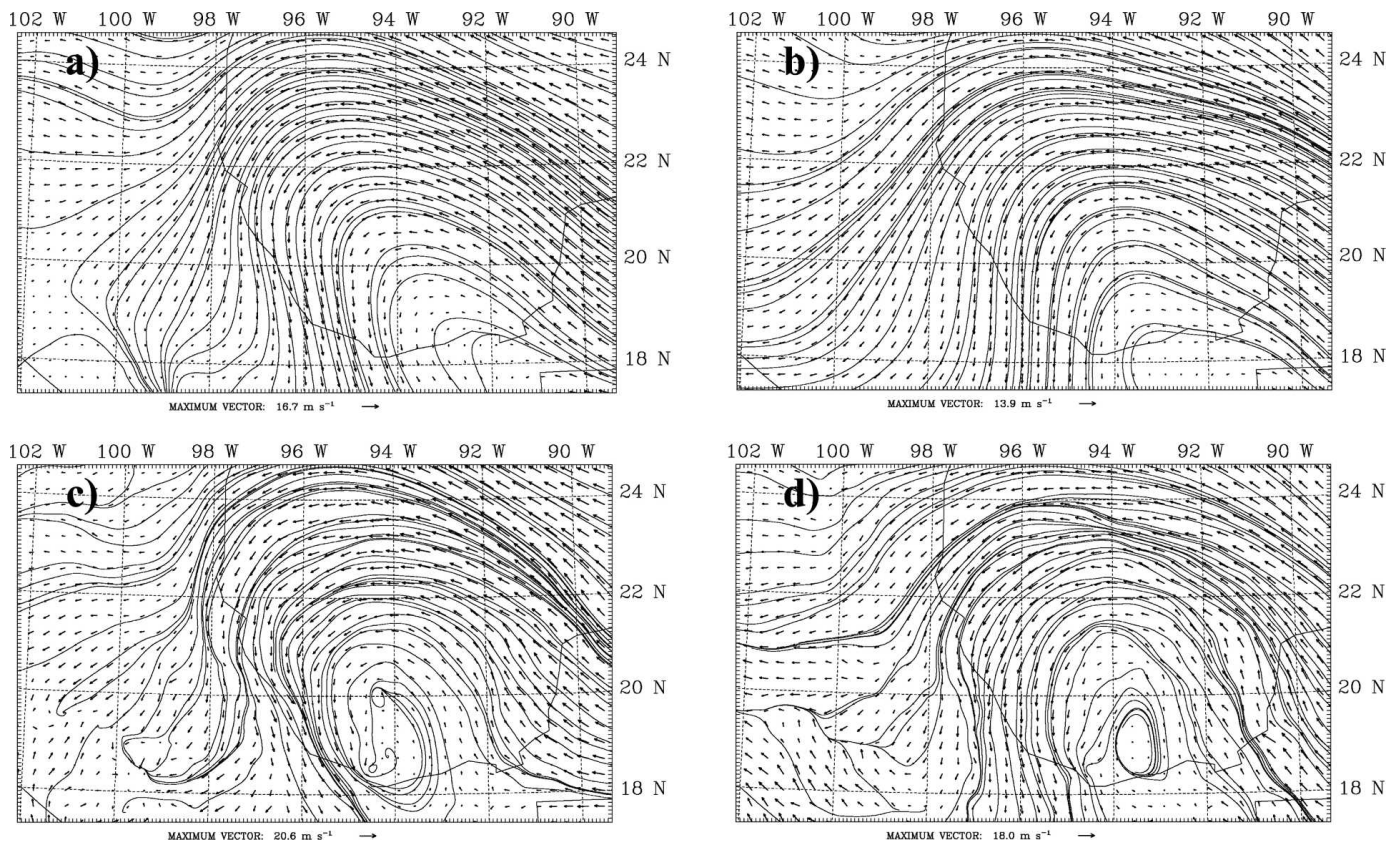

FIG. 15. The analysis of the streamline and wind vector at (left panels) 850 and (right panels) $700 \mathrm{hPa}$ from (bottom) RUC-9, compared with (top) first-guess fields from CTRL, for Gert at 0000 UTC 24 Jul 2005.

1-h RUC data assimilation cycle was performed during the same analysis period on the 9-km domain (RUC-9) for Cindy. Forecasts were compared with the CTRL.

Figure 16 shows the initial conditions at 0000 UTC 5 July 2005 for Cindy before and after data assimilation in ALL-27 and illustrates that the depiction of the tropical storm has been improved after the assimilation. A closed center of low pressure was reproduced and the magnitude of the minimum pressure is closer to that reported from the observations. Note that the storm center was tracked by an algorithm described in Marchok (2002) for the initial conditions before data as- similation, in which the closed circulation was not clearly shown.

Figure 17 shows that the track forecast was significantly improved by assimilation of the data. The track error was reduced by up to $50 \%$ in experiment ALL-27 and by more than $70 \%$ in experiment RUC- 9 , indicating that the storm and environmental conditions are better represented by those experiments. The landfall time and location are well captured by the forecast with data assimilation. In the CTRL, the storm made landfall at 1200 UTC 6 July 2005, about $6 \mathrm{~h}$ behind the actual landfall time. With the data assimilation, the
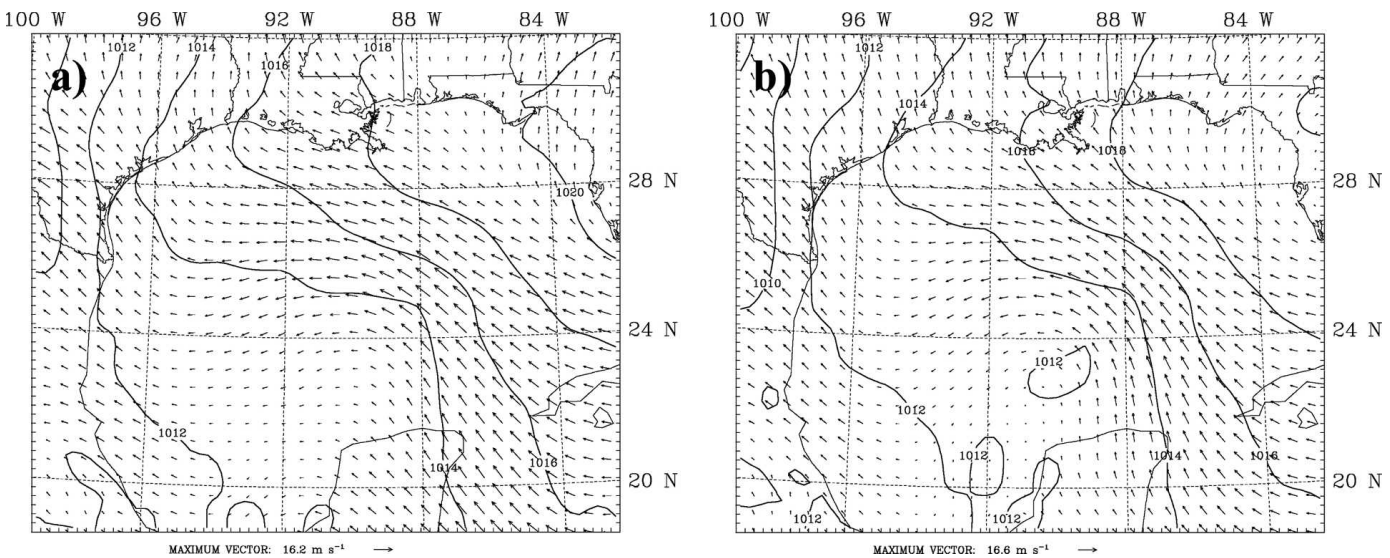

FIG. 16. The sea level pressure and vector wind at $0.5 \mathrm{~km}$ at 0000 UTC 5 Jul 2005 for Tropical Storm Cindy for (a) CTRL and (b) ALL-27. 


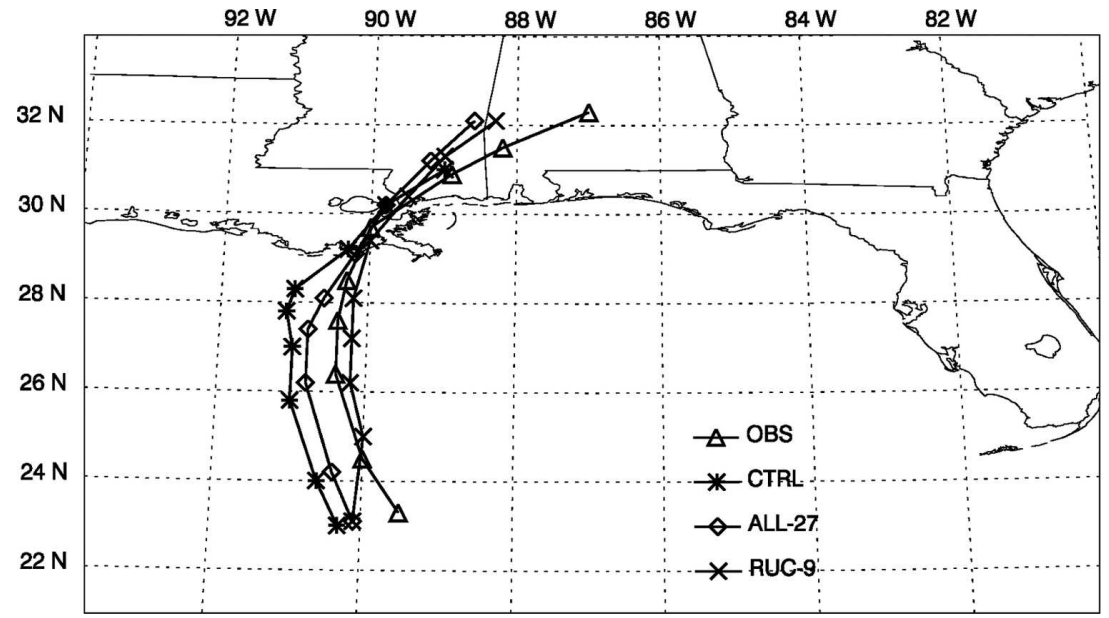

FIG. 17. Tropical Storm Cindy's track forecast during 0000 UTC 5 Jul-0000 UTC 7 Jul 2005, from the CTRL and the experiments with all data assimilated (ALL-27 and RUC-9) compared with the observed track. Center locations along the tracks are indicated every $6 \mathrm{~h}$.

model forecast was able to capture a landfall time that is much closer to the observed landfall time. In addition, with the benefit of data assimilation, the forecast storm track is approaching the observed track when compared with the CTRL, in which the storm moved too slowly after the landfall. However, in both cases (with and without data assimilation), the track error tends to be large after the storm makes landfall. This may be caused by the lack of high-resolution land surface information in the model.
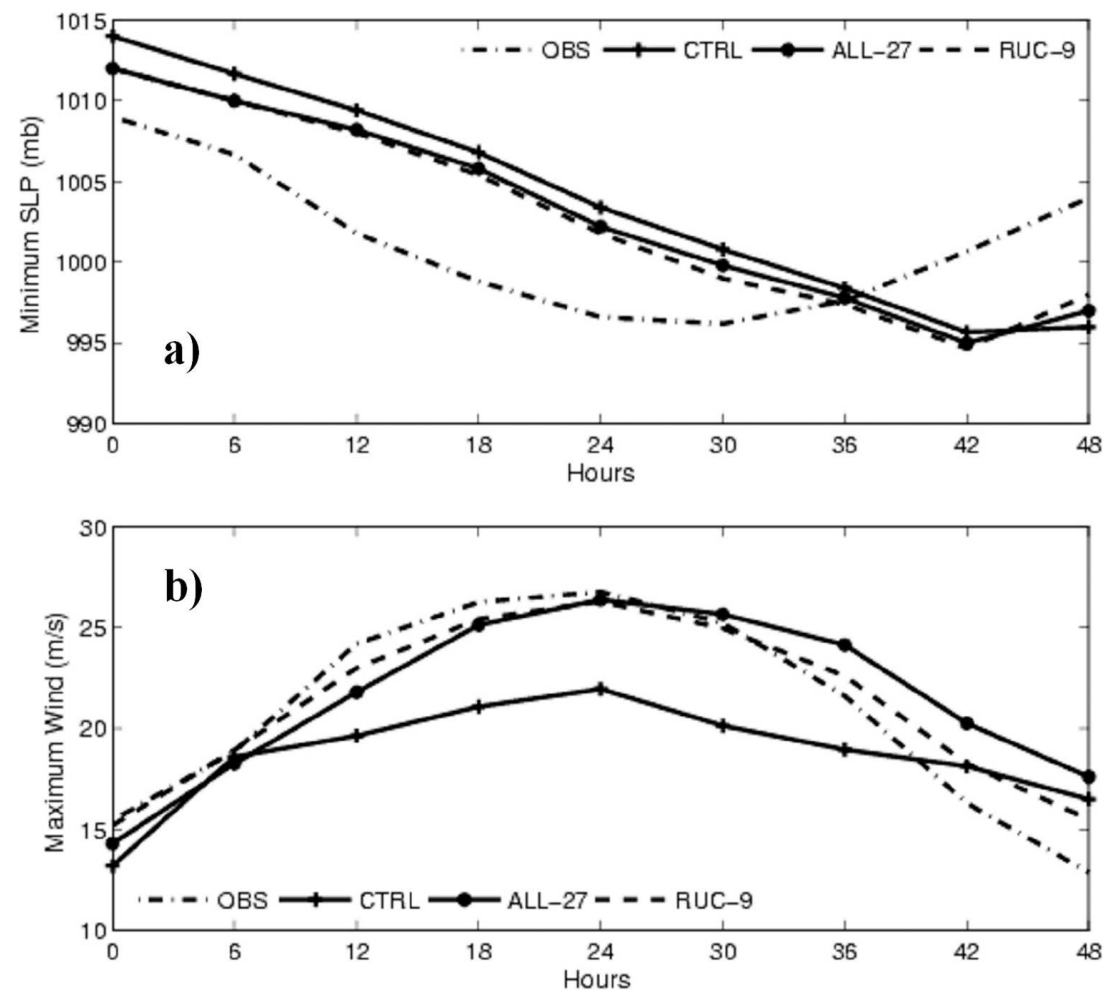

FIG. 18. Time series (at 6-h intervals) of (a) minimum sea level pressure (hPa) and (b) maximum winds $\left(\mathrm{m} \mathrm{s}^{-1}\right)$ at the surface $(10 \mathrm{~m})$ during 0000 UTC 5 Jul-0000 UTC 7 Jul 2005. 
Figure 18 illustrates the time variation of storm intensity in terms of minimum sea level pressure and maximum surface wind speed. The intensity of the storm is indeed improved with assimilation of the added datasets. Compared with experiment ALL27, RUC-9 produces a better intensity forecast for Cindy.

Figure 19 compares the 48-h accumulated precipitation along the storm track with corresponding rainfall estimations from the TMI, Special Sensor Microwave Imager (SSM/I), and IR rainfall observational products [NASA TRMM real-time rainfall products; Huffman (2007)]. The model produces unrealistically huge amounts of rainfall after landfall in the CTRL (Fig. 19b). This accumulated heavy rainfall mainly reflects the slower movement of the storm in the CTRL. The large precipitation accumulation before the storm made landfall was missed. In contrast, with the added data assimilated, the model was able to more realistically reproduce the features of observed rainfall accumulation both before and after the storm made landfall (Fig. 19c).

To further provide support that the data assimilation improves the quantitative precipitation forecast (QPF), a comparison is illustrated by histograms of the probability density function (PDF) for the 48-h accumulated rainfall (Fig. 20). The PDF usually represents the rainfall probability distribution in different magnitude ranges. Figure 20 shows that rainfall is generally overestimated in the low rainfall and underestimated in the high rainfall in the CTRL experiment. However, with data assimilation, the spectrum of rainfall becomes closer to the observed. Specifically, RUC-9 produces a better forecast compared with ALL-27.

\section{Summary and conclusions}

The impacts of dropwindsonde observations, QuikSCAT near-surface vector winds, and GOES-11 rapidscan atmospheric motion vectors on WRF forecasts of two landfalling tropical cyclones (Cindy and Gert in 2005) during NASA's TCSP experiment are evaluated in this study. It is shown that there is a clear benefit to assimilating all three types of the data from dropwindsondes and satellites, which result in positive impacts on track, intensity, and precipitation forecasts for both Cindy and Gert. The forecast landfall time and location are also improved. The in situ and satellite data collected during the TCSP field program are useful data sources for studying tropical cyclones.

In addition, new findings from this study using the WRF mesoscale model and data assimilation system include the following: 1) Assimilation of QuikSCAT
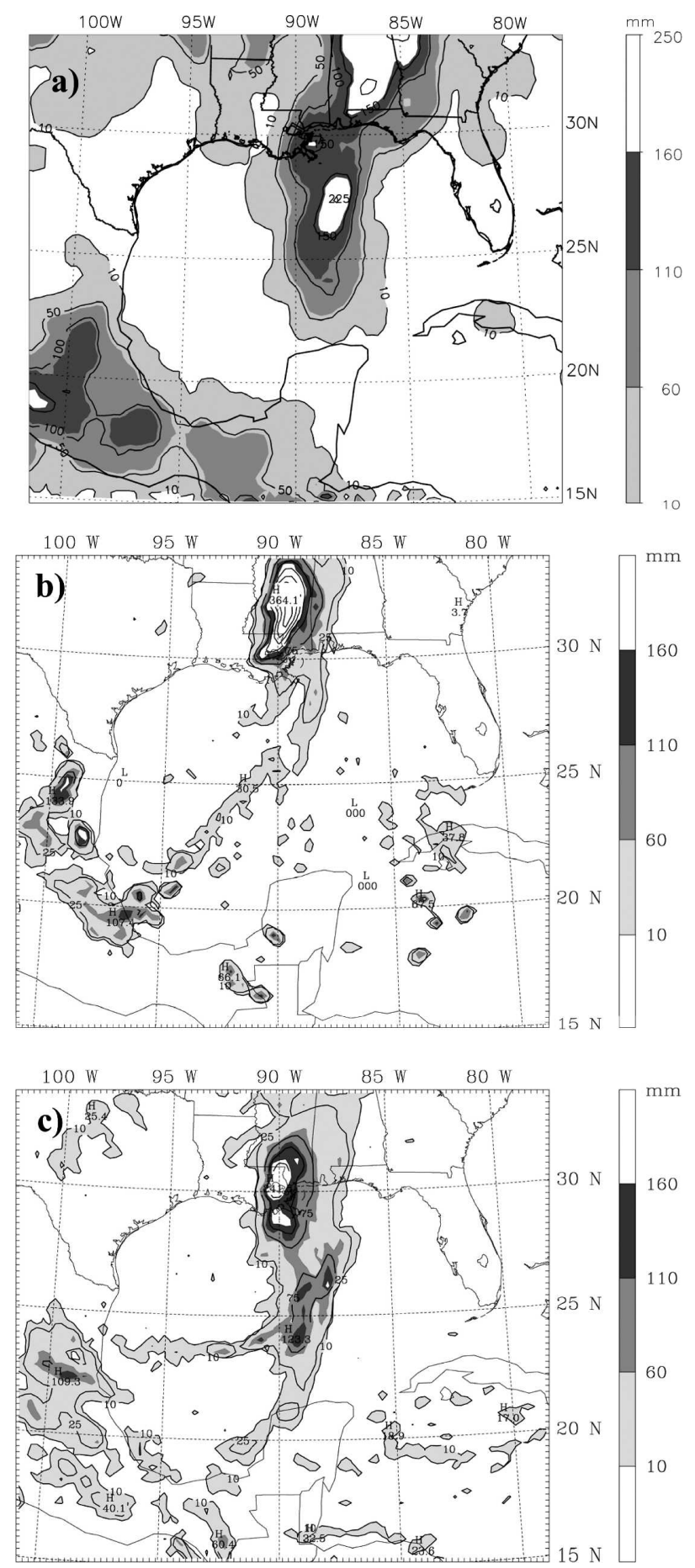

FIG. 19. Forecast 48-h accumulated rainfall amount (mm) during 0000 UTC 5 Jul-0000 UTC 7 Jul 2005, compared with the rainfall totals from TRMM real-time products merged from multiple satellites along the storm track during the same period. (a) TRMM real-time rainfall products merged from multisatellite observations, (b) CTRL, and (c) ALL-27. 


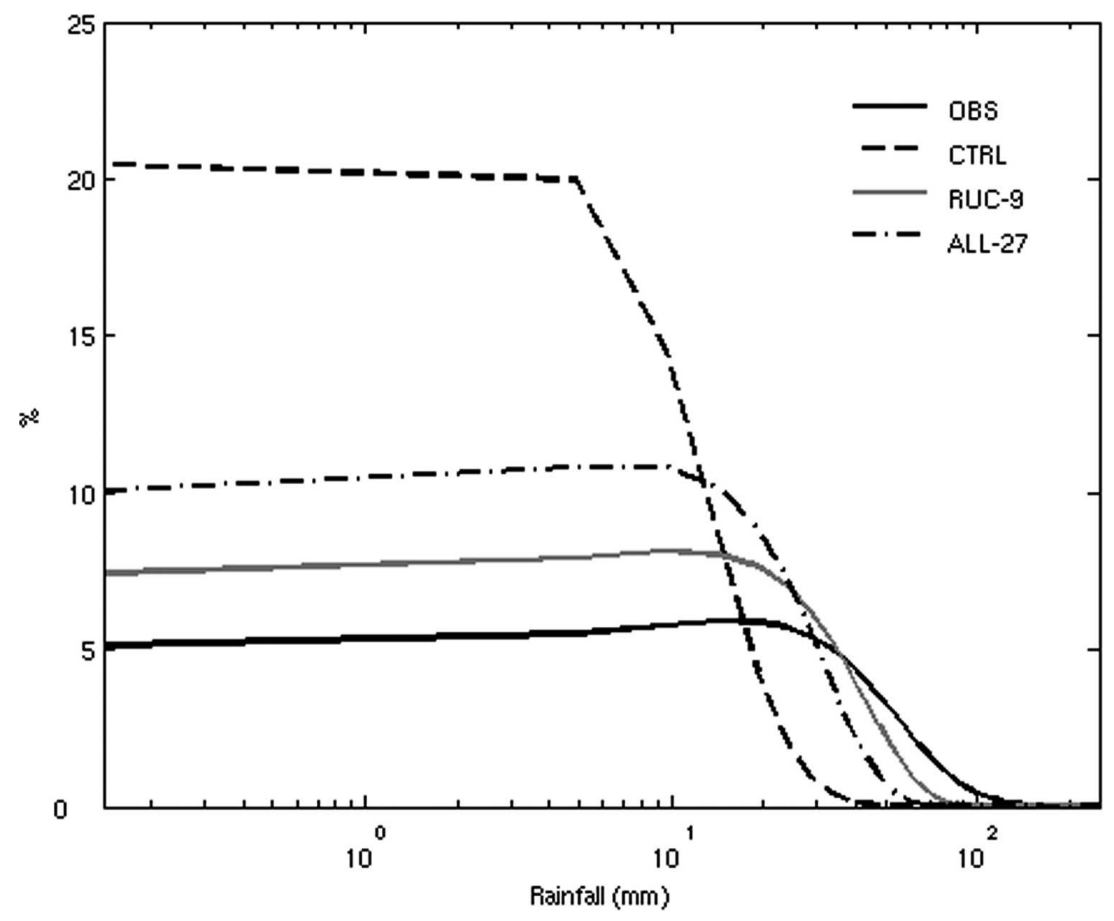

FIG. 20. Histograms of PDFs of the 48-h accumulated rainfall amount for experiments RUC-9, ALL-27, and CTRL, compared with PDFs of the 48-h accumulated rainfall amount from TRMM real-time rainfall products merged from multisatellite observations.

wind data mainly contributes to improvements in the track forecasts as the impact of the QuikSCAT surface vector winds extended well above the surface (Figs. 12a and $12 \mathrm{~b}$ ), whereas the GOES AMV and dropwindsonde data are necessary for improving the forecasts of the intensity and precipitation. 2) Compared with a regular 6-h analysis cycle at coarser resolution $(27 \mathrm{~km})$, a 1-h rapid update analysis cycle at high resolution (9 $\mathrm{km}$ ) shows additional promise for improving forecasts of tropical cyclones. 3) Data assimilation helped the model to produce more realistic QPFs near the landfalls for both Cindy and Gert.

Furthermore, compared with the results from the assimilation of any single data type, assimilation of all three data types together improves the fit of the initial analysis to each and every type of the data (Figs. 4-6). The improved analyses and forecasts from assimilation of all three types of data imply that the information provided by different types of data may be complementary to each other. The differences in precipitation structures from forecasts with assimilation of various data types can be attributed to the data's impact on the overall convergent-divergent flow of the vortex and vertical wind shear in the storm environment (Figs. 1012).

Overall, the data assimilation results from this study are quite positive. As 3DVAR is usually computation- ally efficient, this suggests that a high-resolution rapidly updated 3DVAR analysis might be a practical way to assimilate the data collected from tropical cyclone field experiments. A WRF four-dimensional variational data assimilation (4DVAR) system is currently under development (Huang et al. 2006), so there is still an open question as to whether the rapidly updated data assimilation results will be compatible with the those from a 4DVAR data assimilation, even though 4DVAR is generally computationally expensive. Therefore, more questions can be addressed in detail in the future work. In addition, since the two cases studied in this paper were weak tropical storms and their intensity changes during the whole period of the studies were relatively small, general conclusions must await future studies.

Acknowledgments. The authors would like to acknowledge the WRF model and 3DVAR working groups for their efforts to develop the community WRF model systems. The authors would also like to acknowledge NOAA/NESDIS for providing the GOES-11 rapid-scan data, and Howard Berger and Dave Stettner at CIMSS for processing and providing the GOES-11 winds.

This study was supported by the NASA TCSP program through partial support to the first three authors. The first two authors are very grateful to Drs. Edward 
Zipser and Ramesh Kakar for their support and encouragement during this study. Two anonymous reviewers and Prof. Da-Lin Zhang from University of Maryland are also greatly appreciated for their valuable comments on the manuscript.

The computer time for this study was provided by the Center for High Performance Computing (CHPC) at the University of Utah.

\section{REFERENCES}

Aberson, S. D., 2002: Two years of operational hurricane synoptic surveillance. Wea. Forecasting, 17, 1101-1110.

_ , and C. R. Sampson, 2003: On the predictability of tropical cyclone tracks in the northwest Pacific basin. Mon. Wea. Rev., 131, 1491-1497.

- and B. J. Etherton, 2006: Targeting and data assimilation studies during Hurricane Humberto (2001). J. Atmos. Sci., 63, 175-186.

Barker, D. M., W. Huang, Y. R. Guo, and Q. N. Xiao, 2004a: A three-dimensional data assimilation system for use with MM5: Implementation and initial results. Mon. Wea. Rev., 132, 897-914.

—, M.-S. Lee, Y.-R. Guo, W. Huang, Q.-N. Xiao, and R. Rizvi, 2004b: WRF variational data assimilation development at NCAR. Preprints, WRF/MM5 Users' Workshop, Boulder, CO, NCAR, 5.1. [Available online at http://www.mmm. ucar.edu/mm5/workshop/workshop-papers_ws04.html.]

Betts, A. K., 1986: A new convective adjustment scheme. Part I: Observational and theoretical basis. Quart. J. Roy. Meteor. Soc., 112, 677-691.

—_, and M. J. Miller, 1986: A new convective adjustment scheme. Part II: Single column tests using GATE wave, BOMEX, ATEX and arctic air-mass data sets. Quart. J. Roy. Meteor. Soc., 112, 693-709.

Beven, J. L., II, and Coauthors, 2008: The Atlantic hurricane season of 2005. Mon. Wea. Rev., in press.

Burpee, R. W., S. D. Aberson, J. L. Franklin, S. L. Lord, and R. E. Tuleya, 1996: The impact of Omega dropwindsondes on operational hurricane track forecast models. Bull. Amer. Meteor. Soc., 77, 925-933.

Chen, S.-H., 2007: The impact of assimilating SSM/I and QuikSCAT satellite winds on Hurricane Isodore simulation. Mon. Wea. Rev., 135, 549-566.

Dudhia, J., 1989: Numerical study of convection observed during the Winter Monsoon Experiment using a mesoscale twodimensional model. J. Atmos. Sci., 46, 3077-3107.

Elsberry, R. L., and F. D. Marks, 1999: The Hurricane Landfall Workshop summary. Bull. Amer. Meteor. Soc., 80, 683-685.

Frank, W. M., and E. A. Ritchie, 1999: Effects of environmental flow upon tropical cyclone structure. Mon. Wea. Rev., 127, 2044-2061.

Franklin, J. L., and M. DeMaria, 1992: The impact of Omega dropwindsonde observations on barotropic hurricane track forecasts. Mon. Wea. Rev., 120, 381-391.

— S. J. Lord, S. E. Feuer, and F. D. Marks, 1993: The kinematic structure of Hurricane Gloria (1985) determined from nested analyses of dropwindsonde and Doppler radar data. Mon. Wea. Rev., 121, 2433-2451.

Halverson, J. B., and Coauthors, 2007: NASA's Tropical Cloud Systems and Processes Experiment: Investigating tropical cy- clogenesis and hurricane intensity change. Bull. Amer. Meteor. Soc., 88, 867-882.

Hong, S.-Y., and H.-L. Pan, 1996: Nonlocal boundary layer vertical diffusion in a medium-range forecast model. Mon. Wea. Rev., 124, 2322-2339.

Hou, A. Y., S. Q. Zhang, and O. Reale, 2004: Variational continuous assimilation of TMI and SSM/I rain rates: Impact on GEOS-3 hurricane analyses and forecasts. Mon. Wea. Rev., 132, 2094-2109.

Houze, R. A., and Coauthors, 2006: The Hurricane Rainband and Intensity Change Experiment: Observations and modeling of Hurricanes Katrina, Ophelia, and Rita. Bull. Amer. Meteor. Soc., 87, 1503-1521.

Huang, X.-Y., and Coauthors, 2006: Preliminary results of WRF 4D-Var. Preprints, Seventh Annual WRF Users' Workshop, Boulder, CO, NCAR, 4.5. [Available online at http:// www.mmm.ucar.edu/wrf/users/workshops/WS2006/ WorkshopPapers.htm.]

Huffman, G. J., cited 2007: README for accessing experimental real-time TRMM Multi-satellite Precipitation Analysis (TMPA-RT) data set. [Available online at ftp:// trmmopen.gsfc.nasa.gov/pub/merged/3B4XRT_README.]

Kakar, R., M. Goodman, R. Hood, and A. Guillory, 2006: Overview of the Convection and Moisture Experiment (CAMEX). J. Atmos. Sci., 63, 5-18.

Kalnay, E., 2003: Atmospheric Modeling, Data Assimilation and Predictability. Cambridge University Press, $340 \mathrm{pp}$.

Lorenc, A. C., 1986: Analysis methods for numerical weather prediction. Quart. J. Roy. Meteor. Soc., 112, 1177-1194.

Marchok, T. P., 2002: How the NCEP tropical cyclone tracker works. Preprints, 25th Conf. on Hurricane and Tropical Meteorology, San Diego, CA, Amer. Meteor. Soc., P1.13.

Mlawer, E. J., S. J. Taubman, P. D. Brown, M. J. Iacono, and S. A. Clough, 1997: Radiative transfer for inhomogeneous atmosphere: RRTM, a validated correlated-k model for the longwave. J. Geophys. Res., 102 (D14), 16 663-16 682.

Parrish, D. F., and J. C. Derber, 1992: The National Meteorological Center's spectral statistical-interpolation analysis system. Mon. Wea. Rev., 120, 1747-1763.

Pu, Z.-X., and S. Braun, 2001: Evaluation of bogus vortex techniques with four-dimensional variational data assimilation. Mon. Wea. Rev., 129, 2023-2039.

_ , and W.-K. Tao, 2004: Mesoscale assimilation of TMI data with 4DVAR: Sensitivity study. J. Meteor. Soc. Japan, 82, 1389-1397.

,-- , S. Braun, J. Simpson, Y. Jia, J. Halverson, A. Hou, and W. Olson, 2002: The impact of TRMM data on mesoscale numerical simulation of Supertyphoon Paka. Mon. Wea. Rev., 130, 2248-2258.

Rogers, R., S. Chen, J. Tenerelli, and H. Willoughby, 2003: A numerical study of the impact of vertical shear on the distribution of rainfall in Hurricane Bonnie (1998). Mon. Wea. Rev., 131, 1577-1599.

Skamarock, W. C., J. B. Klemp, J. Dudhia, D. O. Gill, D. M. Barker, W. Wang, and J. G. Powers, 2005: A description of the Advanced Research WRF Version 2. NCAR Tech. Note NCAR/TN-468+STR, 88 pp.

Smolarkiewicz, P. K., and G. A. Grell, 1992: A class of monotone interpolation scheme. J. Comput. Phys., 101, 431-440.

Velden, C. S., C. M. Hayden, W. P. Menzel, J. L. Franklin, and J. S. Lynch, 1992: The impact of satellite-derived winds on numerical hurricane track forecasting. Wea. Forecasting, 7, 107-118. 
- - , S. Nieman, W. P. Menzel, S. Wanzong, and J. Goerss, 1997: Upper -tropospheric winds derived from geostationary satellite water vapor observations. Bull. Amer. Meteor. Soc., 78, 173-195.

— T. L. Olander, and S. Wanzong, 1998: The impact of multispectral GOES-8 wind information on Atlantic tropical cyclone track forecasts in 1995. Part I: Dataset methodology, description, and case analysis. Mon. Wea. Rev., 126, 12021218.

—- and Coauthors, 2005: Recent innovations in deriving tropospheric winds from meteorological satellites. Bull. Amer. Meteor. Soc., 86, 205-223.

Wentz, F. J., and D. K. Smith, 1999: A model function for the ocean normalized radar cross section at $14 \mathrm{GHz}$ derived from NSCAT observations. J. Geophys. Res., 104, 11 499-11 514.
Wu, C.-C., K.-H. Chou, Y. Wang, and Y.-H. Kuo, 2006: Tropical cyclone initialization and prediction based on fourdimensional variational data assimilation. J. Atmos. Sci., 63, 2383-2395.

Wu, W.-S., R. J. Purser, and D. F. Parrish, 2002: Threedimensional variational analysis with spatially inhomogeneous covariances. Mon. Wea. Rev., 130, 2905-2916.

Zhang, D.-L., and C. Q. Kieu, 2006: Potential vorticity diagnosis of a simulated hurricane. Part II: Quasi-balanced contributions to forced secondary circulations. J. Atmos. Sci., 63, 2898-2914.

Zhu, T., D.-L. Zhang, and F. Weng, 2002: Impact of the Advanced Microwave Sounding Unit measurements on hurricane prediction. Mon. Wea. Rev., 130, 2416-2432. 